1 Adoption of environment-friendly agricultural practices with 2 background risk: experimental evidence.

3

\author{
Lefebvre, Marianne, GRANEM n 7456, UNIV Angers, IUT d'Angers, SFR Confluences, F-49036 \\ Midler, Estelle, IUSF, Osnabrück University, D-49069 \\ Bontems, Philippe, Toulouse School of Economics, INRAE, University of Toulouse Capitole, F- \\ 31000 \\ Corresponding author: marianne.lefebvre@univ-angers.fr
}

\title{
Abstract
}

Agriculture is one of the economic sectors most exposed to exogenous risks such as climate hazards and price volatility on agricultural markets. Agricultural policies targeting the adoption of environment-friendly but potentially risk-increasing practices cannot ignore this challenge. Farmers have indeed to decide if they take the foreground risk associated with the adoption of environmentfriendly practices, while simultaneously facing exogenous background risk beyond their control. Using a theoretical model and a public good experiment, we analyse the adoption of agrienvironmental practices and the effect of agri-environmental subsidies in a context where risks are both foreground and background. While most of the literature on background risk focuses on its impact on individual decisions, we analyse the influence of background risk in a context of strategic uncertainty (contribution to a public good). The results highlight the potential synergies between greening the CAP and supporting risk management. We find that background risk discourages the adoption of green practices, although it affects all farmland independently from the farmer's choice of practices (environment friendly or conventional). An incentive payment per hectare of land farmed with green practices increases the adoption of risk-increasing practices but is significantly less effective in the presence of background risk.

JEL codes: C93, D81, Q18, Q12

Keywords: Common Agricultural Policy, Agri-environmental measures, Background risk, Lab experiment, Risk aversion, Public good game

Acknowledgments: The survey on which this paper is based was funded by Angers University in the context of the project "Verdissement de la politique agricole européenne: étude expérimentale des réactions des agriculteurs". However, the views expressed are purely those of the authors and may not in any circumstances be regarded as stating an official position of the University. The authors would like to thank S. Blondel for his comments on the experimental design and a draft version of the article, B. Goujon for programming the on-line survey and M. Ghali for recruiting the subject at Ecole Supérieure d'Agricultures d'Angers. Estelle Midler acknowledge fundings from the Alexander Von Humboldt foundation in the framework of the Alexander Von Humboldt professorship endowed by the German federal ministry of research and education. Philippe Bontems acknowledges funding from ANR under grant ANR-17-EURE-0010 (Investissements d'Avenir program). 
3 One of the main challenges facing EU agriculture and its common policy post 2020, is to foster the adoption of environment-friendly agricultural practices and sustainable land management (European

5 Commission 2017). To do this, consideration should be given to how to motivate farmers to better manage the environment in an effective and efficient way.

7 There are multiple barriers to the adoption of environment friendly farming practices. First, a farmer 8 may be reluctant to bear individually the costs of their implementation, since the benefits created will 9 be distributed collectively. For example, the maintenance of hedgerows promotes pollination 10 services or natural regulation by crop auxiliaries in neighbouring farms. To overcome this public 11 good dilemma, incentive schemes have been set up in the EU since the late nineties with the aim of 12 encouraging farmers to adopt practices beneficial for the environment under multiannual contracts. 13 These so-called agri-environmental measures are designed to compensate for the costs faced by 14 farmers when they implement such practices ${ }^{1}$.

15 Second, adopting environment-friendly practices sometimes leads to greater variability in yields and 16 costs (Knapp and Heijden 2018) not easily accepted by risk-averse farmers (Binswanger 1980; 17 Chavas and Holt 1996; Bocquého, Jacquet and Reynaud 2014; Bougherara et al. 2017; Menapace, 18 Colson and Raffaelli 2013; Chèze, David and Martinet 2020). Farmers may choose to avoid the 19 foreground risk of profit variability arising from risk-increasing environment-friendly practices by 20 not engaging in them.

21 In addition, farmers also face risks beyond their control. Agriculture is one of the economic sectors most exposed to exogenous risks (hereinafter referred to as "background risks") such as climate change (or climate hazards more generally) (Herberich and List 2012). While farmers can use various strategies to manage the consequences of climate risks on production (e.g. irrigation, resilient crops) and/or revenues (e.g. income diversification, insurance), these strategies do not always allow for all risks to be pooled or shifted (OECD 2009). Part of the risk inevitably remains in the background. As a result, farmers must decide whether they should adopt potentially risk-increasing practices in an already uncertain environment. In other words, they have to decide whether to bear the foreground (endogenous) risks while simultaneously facing one or more immutable background (exogenous) risks. Taking into account the background risk could thus significantly improve our understanding of behaviours in many contexts, including the decision to adopt risky and

\footnotetext{
1 While, in theory, agri-environmental measures aim at compensating the total costs of implementing environmentfriendly practices, it is not always the case in practice. First, because it provides a fixed payment to farmers, calculated on the average costs in a given region. As a result, some farmers, facing higher costs, have no incentive to contract such measures. Second, because additional costs, such as transaction or learning costs, are not always accounted for in the design of the payments. This increases the total costs for farmers, who, in turns, have no incentive to engage in such contracts (Ducos, Dupraz and Bonnieux 2009; Espinosa-Goded, Barreiro-Hurlé and Dupraz 2013). While this is an important barrier to agri-environmental measures adoption, this is not the main focus of our paper. Here, we only consider payments that cover the full costs of implementation.
} 
environment-friendly practices. In this multiple risks context, it is well known that the optimal risk-

2 taking decision on a particular risk is generally not independent of the existence of other risks, even

3 if these risks are independent (Gollier 2001). Whether agents make more or less risky decisions when

4 the riskiness of the environment itself changes depends on assumptions about preferences (Gollier 5 and Pratt (1996), Eeckhoudt, Gollier and Schlesinger (1996), Diamond (1984), Quiggin (2003)). Therefore, understanding the effect of background risk on risk-taking behaviours remains an empirical question. ${ }^{2}$

While agri-environmental measures aim to offset the full costs of environment-friendly practices implementation, their design does not take these two types of risks (foreground and background risk) into account. Therefore, even with these measures, farmers could still refrain from adopting such practices in order to avoid the variability of profits associated with them in an already uncertain context.

13 The purpose of this paper is twofold. First, we analyse the importance of background risk on decisions to adopt environmentally sound practices (whether risky or not) in a context of strategic uncertainty. Second, we assess how incentive payments, similar to those proposed under the CAP to promote sustainable agriculture, are effective in triggering the adoption of environment-friendly practices in the presence of foreground and/or background risk.

18 To do so, we begin by developing a simple theoretical model to study how farmers allocate their land between environment-friendly and conventional practices (a portfolio decision) and how this decision is influenced by the presence of foreground and background risks, as well as a certain incentive payment. In our framework, a producer's individual gain depends both on his or her own contribution to environment-friendly farming and on the total area cultivated with such green practices in the group. These practices are assumed to be more costly and riskier than conventional practices. The marginal return from agriculture is uncertain, regardless of the practices used, due to production, price and policy uncertainties, and this constitutes the background risk. To simplify, we assume that preferences over the random ex-post wealth can be represented by a two-moment utility function (Meyer, 1987). We prove that, under DARA preferences, the game between farmers is with strategic complementarities. As a consequence, there is potentially too little land cultivated with environment-friendly practices compared to the situation where farmers cooperate perfectly. In addition, among other results, we show three main findings: (i) the presence of foreground risk reduces the adoption of environment-friendly practices, (ii) the presence of background risk reduces

\footnotetext{
${ }^{2}$ Laboratory and field experiments have been designed to test whether background risk affects the risk behavior of individuals. Laboratory experiments conducted by Lusk and Coble (2008), Lee (2008) and Beaud and Willinger (2014) concluded that an individual exposed to background risk (whether fair or unfair) would be willing to take fewer foreground risk. With regards to field experiments, Harrison et al. (2007) find that increasing background risk increases risk aversion in the U.S. rare coins market. In contrast, Bchir and Willinger (2013) found that Peruvians living in highrisk areas (due to volcano mudflows) are less risk-averse than those living with lower background risk levels, but their result holds only for low income individuals (no significant results for higher incomes). Herberich and List (2012) carried out an experiment similar to that of Harrison et al. (2007) comparing US farmers and students, but they find no conclusive results regarding the impact of background risk on risk aversion.
} 
1 the adoption of green farming practices but only when they are risky and (iii) the incentive payment 2 increases the adoption of green farming practices in all risks contexts.

3 In a second step, we conducted a framed lab experiment based on a public good game in order to test 4 the empirical validity of the three results described above. The experiment is contextualized to 5 capture the context of European agriculture and the subject pool consists of future agriculture stakeholders (students in agriculture). We observe that adopting green farming practices is indeed 7 less likely when they are risky (as in (i)). We also find that background risk can reduce the willingness to engage in environment-friendly practices with public good properties, but even if there 9 are not risk-increasing (as opposed to the theoretical result (ii)). Moreover, we highlight that a given 10 incentive payment can efficiently increase the adoption of green practices when only one source of 11 risk exists but can fail to do so in the presence of both foreground and background risks (therefore 12 qualifying result (iii)).

13 Our analysis adds to the sparse literature investigating the production decisions of risk-averse 14 farmers in the presence of multiple risks (Coyle 1999; Isik 2002; Serra et al. 2006; Ridier, Chaib and 15 Roussy 2016; Bontems and Nauges 2019). ${ }^{3}$ In particular, we contribute to the literature by analysing 16 the influence of background risk on cooperative decisions, in a context of strategic uncertainty. Most of the literature on background risk is in the field of finance and focuses on its impact on individual portfolio decisions. In strategic context, only the impact of foreground risk has been analysed, in particular in the experimental literature applied to environmental issues based on public good games (Dickinson 1998; Gangadharan and Nemes 2009; Levati, Morone and Fiore 2009; Levati and Morone 2013). We contribute to the literature by testing whether the presence of background risk reduces the voluntary contribution to a public good (with and without foreground risk).

23 The paper is organized as follows. Section 2 presents the modelling framework, section 3 the experimental design, and section 4 the experimental results. In section 5, we discuss the policy implications and limitations of the study while section 6 concludes.

\footnotetext{
${ }^{3}$ There are many different risk taxonomies in the agricultural economics literature (see OECD (2009) for a review of the different classifications of agricultural risks). For example, one can distinguish between output and price uncertainty, sometimes including other sources such as technological or policy uncertainty (Moschini and Hennessy 2001). Another useful categorization in dynamic context is that of "non-embedded risks », i.e. risks that are beyond control of the decision maker because all decisions are made initially, versus « embedded risks », i.e. risks that can be influenced by farmers' adaptive behaviour due to sequential decisions (Hardaker, Pandey and Patten 1991; Dorward 1999; Ridier, Chaib and Roussy 2016). While both taxonomies are certainly relevant, we rely here on another one to distinguish between background risk (which is beyond farmers' control and affects all crops) and foreground risk (which only affects crops grown according to environment-friendly practices: Farmers may therefore choose to avoid the foreground risk by not engaging in such practices).
} 


\subsection{The farmer's problem}

3 Each farmer disposes of $L_{i}$ hectares (exogenous endowment, equal for all players) and has to decide

4 how much of this land is farmed with environment-friendly practices ( $g_{i} \leq L_{i}$ hectares) or with 5 conventional ones $\left(L_{i}-g_{i}\right.$ hectares). Since green farming benefits the group (through ecosystem 6 services), the individual's payoff depends both on her/his own contribution to green farming $\left(g_{i}\right)$ and 7 on the total area farmed with green practices in the group $\left(\sum_{i=1}^{n} g_{i}\right)$.

8 The net private benefits of agriculture depends on the financial returns $\left(b L_{i}\right)$, minus the costs 9 multiplied by the number of hectares cultivated with each type of practice. The financial returns per 10 hectare $b$ include the price, the yield and the base CAP payment (first pillar), and are assumed to be 11 the same for both types of practices. ${ }^{4}$ Environment-friendly practices are assumed to be on average 12 more expensive than conventional practices $\left(c_{g}>c_{c}\right)$, as alternative management strategies can be 13 more labour-intensive and generate learning costs ${ }^{5}$.

14 To account for the public good nature of the services provided by the adoption of environment15 friendly practices, our game is similar to a public good game: when one unit of land is environment16 friendly farmed, $\beta\left(g_{i}+\delta g_{-i}\right)$ points are earned by a farmer in the neighbourhood, where $g_{-i}=$ $17 \sum_{j \neq i} g_{j}$ is the sum of other farmers' actions. The parameter $\beta>0$ is the green land efficiency factor, 18 corresponding to the ecosystem services associated with green practices. The parameter $\delta \geq 0$ is a scaling factor allowing for a differentiated efficiency of personal green land and others' green land. In the limit case where $\delta=0$, each farmer does not benefit from the actions of others: there is no strategic uncertainty.

The adoption of environment-friendly practices can be supported by an incentive payment scheme: $P A Y$ per hectare. The agri-environmental schemes of the rural development policy and the green payment of the first pillar of the CAP can be seen as two examples of instruments that are conditional on the respect of certain environmental standards or practices.

Overall, the payoff function of farmer $i$ is defined as

$$
\pi_{i}=b L_{i}-c_{c}\left(L_{i}-g_{i}\right)-c_{g} g_{i}+\beta\left(g_{i}+\delta g_{-i}\right)+P A Y g_{i}
$$

It is convenient to rewrite this expression as follows:

$$
\pi_{i}=\varepsilon L_{i}+a g_{i}+\beta \delta g_{-i}
$$

\footnotetext{
${ }^{4}$ Indeed, most environmentally friendly practices do not provide access to different prices for the products since they cannot be labelled or certified or are not well-known by the consumers (Bazoche et al. 2013). Moreover, there is no consensus on the impact of environment-friendly practices on yields and yields variability, notably because yield level has many determinants interacting with each other (Lechenet et al. 2017). Finally, CAP direct payments are paid whatever the choice of practices made by a farmer (as long as the land is maintained in good agricultural and environmental conditions and the three greening requirements are fulfilled).

${ }^{5}$ For example, integrated pest management strategies, such as those based on crop diversification and rotations, are time and information/knowledge intensive, compared to pesticide-based pest management strategy as used in conventional agriculture (Guillou et al. 2013; Lefebvre et al. 2017).
} 
where $\varepsilon=b-c_{c}$ and $a=P A Y-\left(c_{g}-c_{c}-\beta\right)$.

The payoff is decomposed into a term $\varepsilon L_{i}$ proportional to the size of land devoted to farming, a term

$a g_{i}$ proportional to the land devoted to environment-friendly farming, and finally a term $\beta \delta g_{-i}$

proportional to the land devoted to environmentfriendly farming by neighboring farmers. ${ }^{6}$

The parameter $\varepsilon$ is the marginal net benefit of farming which is expressed as the difference between the marginal benefit of farming $b$ and the marginal cost $c_{c}$ of using conventional practices. The parameter $a$ is the additional marginal net benefit of farming that the farmer can obtain by using environment-friendly practices instead of conventional ones. It is expressed as the difference between the incentive payment $P A Y$ and the opportunity cost of $g_{i}$ which is $c_{g}-c_{c}-\beta$. Indeed, the alternative to green farming is to use conventional practices which allows to save some $\operatorname{costs} c_{g}-$ $c_{c}>0$ but entails the loss of not enjoying $\beta$ per unit of land.

\subsection{Modelling foreground and background risks}

13 There are two sources of risk, together with the presence of strategic uncertainty due to the public 14 good nature of the game.

15 First, to account for risks beyond farmers' control, we assume that the marginal benefit $b$ is random 16 with mean $\bar{b}$ and variance $v_{b}$. It follows that $\varepsilon$ is random with mean $\bar{\varepsilon}=\bar{b}-c_{c}$ and variance $v_{\varepsilon}=$ $17 v_{b}$. We assume that the parameters are such that $\bar{\varepsilon}>0$. As a consequence, the payoff component $18 \varepsilon L_{i}$ constitutes a background risk, affecting all the farmland independently from agricultural practices, capturing production uncertainty on yields (for example due to climate hazards), but also price uncertainty and policy uncertainty regarding the size of base CAP payments.

21 Second, environment-friendly practices entail additional risk due to the cost $c_{g}$ which is random with 22 mean $\bar{c}_{g}$ and variance $v_{g}$. It follows that $a$ is random with mean $\bar{a}=c_{c}-\bar{c}_{g}+\beta+P A Y$ and 23 variance $v_{a}=v_{g}$. Under uncertainty with respect to $c_{g}$, the payoff component $a g_{i}$ represents the 24 foreground risk.

25 There is potential correlation between the cost of environment-friendly practices $c_{g}$ and the benefit $b$, which translates into a covariance between the background risk $\varepsilon$ and the foreground risk $a$ that we denote $\sigma_{a \varepsilon}$. This correlation is positive if the cost of environment-friendly practices implementation depends on those same climatic events that influence yields or prices. It is null if the obstacles to environment-friendly farming (translated into higher costs) are specific to such practices. At this stage, we do not impose specific assumptions on the sign of this correlation in order to fit various settings.

32 The farmer's decision about how much land should be devoted to farming employing environment-

33 friendly practices can thus be seen as a portfolio decision for an agent owning an initial and certain

6 The game therefore corresponds to an impure public good game because contributions to the public good generate collective benefits, but also provide private benefits (Narloch, Pascual and Drucker 2012; Midler et al. 2015). 
1 wealth denoted $w_{0}$ and that has preferences over its ex-post final wealth denoted $w_{i}=w_{0}+\pi_{i}$.

2 Added complexity comes from the fact that the decision is taken in a strategic context (where the

3 game is aggregative (Acemoglu and Jensen 2013) and under the presence of a background risk

4 potentially correlated to the foreground risk.

\subsection{The structure of preferences}

6 We assume that preferences over the random ex-post wealth can be represented by a two-parameter utility function $V(\mu, v)$ where $\mu$ and $v$ are the expected value and the variance of ex-post wealth, respectively (following Eichner and Wagener (2011) and Bontems and Nauges (2019) $)^{7}$ ).

9 The expected ex-post wealth $\mu$ is as follows:

$$
\mu\left(g_{i}, L_{i}, g_{-i}\right)=w_{0}+\bar{a} g_{i}+\bar{\varepsilon} L_{i}+\beta \delta g_{-i}
$$

11 and the variance of the ex-post wealth is written as

$$
v\left(g_{i}, L_{i}\right)=v_{a} g_{i}^{2}+v_{\varepsilon} L_{i}^{2}+2 L_{i} g_{i} \sigma_{a \varepsilon} .
$$

13 Note that the variance does not depend on the decision of other farmers, while the expected wealth 14 does.

15 Following Meyer (1987), we assume that $V$ is a $C^{3}$ function with

$$
V_{\mu}>0, V_{v}<0, V_{\mu \mu}<0, V_{\mu v}>0
$$

17 The assumptions $V_{\mu}>0$ and $V_{\mu \mu}<0$ entails that preferences are characterized by risk aversion. Risk 18 neutrality would correspond to $V_{v}=0$. The assumption $V_{\mu v}>0$ is the analogue of prudence in the 19 expected utility framework. The mean-variance counterpart of the Arrow-Prat measure of absolute risk aversion is the marginal rate $\alpha$ of substitution between $\mu$ and $v$ :

$$
\alpha(\mu, v)=-\frac{V_{v}}{V_{\mu}}>0
$$

22 Decreasing absolute risk aversion (DARA) preferences are represented by $\alpha_{\mu}<0$ and it means that

23 the marginal willingness to pay for a reduction in variance decreases when expected wealth 24 increases. Also, variance vulnerability is obtained when $\alpha_{v}>0$, which indicates that the marginal 25 willingness to pay for a reduction in variance increases when wealth becomes more volatile. 26 Following Eichner (2008), when these two conditions are met, the individual is said to be risk

\footnotetext{
${ }^{7}$ Coyle (1999), Isik (2002) Serra et al. (2006) and Bontems and Nauges (2019) have also analyzed farmers' production decisions in a mean-variance framework in the context of multiple risks (including background risk for Bontems and Nauges (2019)). Our contribution extends the analysis of production decisions in a risky environment to a public good game context.
} 
1 vulnerable. Finally, to ensure second-order conditions in optimization programs, we consider that

$2 V(\mu, v)$ is quasi-concave or equivalently that:

$$
\alpha \alpha_{\mu}+\alpha_{v}>0
$$

\subsection{Resolution of the farmer's problem}

5 Farmer $i$ maximize $V(\mu, v)$ with respect to $g_{i}$ that belongs to the compact set $\left[0, L_{i}\right]$ and for given strategies $g_{-i}$ by other farmers:

$$
\max _{g_{i}} U\left(g_{i}, g_{-i}, L_{i}\right) \equiv V\left(\mu\left(g_{i}, L_{i}, g_{-i}\right), v\left(g_{i}, L_{i}\right)\right)
$$

8 Ignoring corner solutions, the first-order condition for an interior solution defines the best-response 9 function $g_{i}^{r}\left(g_{-i}\right)$ such that: ${ }^{8}$

$$
\frac{\partial U}{\partial g_{i}}=V_{\mu} \frac{\partial \mu}{\partial g_{i}}+V_{v} \frac{\partial v}{\partial g_{i}}=0
$$

11 or equivalently

$$
\frac{\partial \mu}{\partial g_{i}}=\alpha(\mu, v) \frac{\partial v}{\partial g_{i}}
$$

13 At equilibrium, the marginal benefit of $g_{i}\left(\frac{\partial \mu}{\partial g_{i}}=\bar{a}>0\right)$ is equalized with its marginal cost $14\left(\alpha(\mu, v) \frac{\partial v}{\partial g_{i}}\right)$. The marginal cost decomposes as the marginal willingness to pay for a reduction in 15 variance times the marginal increase in variance of wealth. Importantly, the best-response decision $16 g_{i}^{r}\left(g_{-i}\right)$ depends on others' decisions only through the expected wealth $\mu$ contained in $\alpha(\mu, v)$.

17 If both the cost of environment-friendly practices $c_{g}$ and the marginal benefit $b$ are known with 18 certainty, the wealth function is linear in the decision variable and therefore the equilibrium is a 19 corner solution: $g_{i}=L_{i}$ if $\bar{a}>0$ or $g_{i}=0$ if $\bar{a}<0$. Note that this decision rule under certainty is 20 independent of the other farmers' actions because the wealth function is additive separable between $21 g_{i}$ and $g_{-i}$. Note also that when there is no foreground risk and only a background risk (thus $v_{a}=$ $\left.22 \sigma_{a \varepsilon}=0\right)$, the variance is constant with respect to the decision $g_{i}$. Because $\frac{\partial \mu}{\partial g_{i}}=\bar{a}$, the equilibrium is 23 once again a corner solution with : $g_{i}=L_{i}$ if $\bar{a}>0$ or $g_{i}=0$ if $\bar{a}<0$.

24 However, in the presence of foreground and background risk, and under DARA preferences, the 25 game is with strategic complementarities between the land use decisions $g_{i}$ for $i=1, \ldots, \mathrm{n}$ (see the

\footnotetext{
${ }^{8}$ The assumption of quasi-concavity for $V(\mu, v)$ implies that the second order condition $\partial^{2} U / \partial g_{i}^{2}<0$ holds.
} 
1 proof in the appendix A.2). The intuition is the following: whenever $\delta>0$, each time the allocation

2 of land to environment-friendly practices by other farmers increases, it brings some additional

3 benefits to the non-stochastic part of wealth for farmer $i$. Under DARA preferences, being richer

4 entails that farmer $i$ is induced to take more risk and hence to increase land use with environment-

5 friendly practices. The main consequence of strategic complementarities is that there is potentially

6 too low contributions compared to a situation where land allocations are decided upon coordination between farmers. As long as $\delta>0$, there is underinvestment from each farmer in $g_{i}$ because it generates a positive externality on others that is not taken into account when each farmer decides unilaterally of its land use allocation.

10 It is also worth noting that the background risk is fair in the sense that its upscaling always raises the

11 expected wealth. In the appendix A.1, we also characterize conditions under which an upscaling of 12 the background risk never decreases the variance of wealth (a condition to be qualified as a risk) and 13 under which it decreases utility so that it can be denoted as undesirable.

\subsection{Theoretical propositions tested in the experiment}

16 The model allows to explore how the land allocation decision between environment-friendly 17 practices and conventional ones is impacted by the presence of foreground and/or background risk, 18 and the existence of an incentive payment. Comparative statics of the model is parsed with details in 19 the appendix A3. In particular, the model allows to draw three propositions, which have been tested 20 in an experiment whose design is detailed in the next section.

21 Proposition 1: Foreground risk reduces the adoption of environment-friendly practices

22 Proposition 2: Background risk reduces the adoption of environment-friendly practices, but 23 only when they are risky

24 Proposition 4: The incentive payment increases adoption of environment-friendly practices in 25 all risk contexts

\section{Experimental design}

28 In order to test the empirical validity of the three propositions above, we have conducted a framed 29 lab experiment based on a public good game. We choose a public good game to capture the 30 ecosystem services provided by environment-friendly practices, such as pollination services or 31 biocontrol, providing benefits for the community. Farmers decide how much of their land they would 32 like to farm according to conventional (corresponding to the private account) or to environment33 friendly practices (corresponding to the public account). 


\section{$3.1 \quad$ Treatments}

2 In order to capture the presence or absence of foreground and background risk, the treatments differ

3 by the volatility of the financial yields and costs.

4 In the benchmark treatment, we consider the case of non-risky environment-friendly practice and participants know the fixed value of the parameters $c_{g}$ and $b$. In the other experimental treatments, 6 we introduce risk on these parameters. In the foreground risk treatment (ForeOnly), participants are 7 informed that $c_{g}$ can be either $c_{g}$ or $\overline{c_{g}}$, each with probability $1 / 2$, corresponding to a risk-increasing 8 practice. In the treatment with background risk only (BackOnly), the financial yield $b$ can be either $9 \underline{b}$ or $\bar{b}$, each with probability $1 / 2$ but $c_{g}$ is known (there is no foreground risk). The fourth treatment 10 (Fore\&Back) corresponds to the realistic situation where participants face both foreground and 11 background risk.

12 All parameters values are available in Table 1. Parameters have been chosen such that the expected 13 profits are equal in all treatments. The background risk affecting financial yields originates from 14 multiple sources of risk, frequently independent of each other and unlikely to cancel each other out. 15 Therefore, we have chosen a volatility greater for the background risk $(\operatorname{Var}(b)=25)$ than for the 16 foreground risk $\left(\operatorname{Var}\left(c_{g}\right)=4\right)$. While the model allows for correlation between the foreground and 17 background risk, the correlation is set to zero in the experiment. This allows to disentangle the 18 impact of these two sources of risks, while their effects would generally be confounded in 19 observational data.

20 In order to study the impact of the introduction of an incentive payment to foster the adoption of environment-friendly practices in those different contexts of risk, a within-subject design is chosen: each participant makes two decisions, without and with the payment. It allows to compare individual contributions in a given risk set-up, before and after the implementation of the instrument. We do not control for order effects since we are not interested in the impact of the withdrawal of this support, which would be an unlikely policy scenario.

The parameter has been chosen such that $a=P A Y-\left(c_{g}-c_{c}-\beta\right)$ is negative in the no payment scenario $(\mathrm{PAY}=0)$ and positive in the payment scenario. In other words, there is a social dilemma in the absence of incentive payment: participants' best private strategy is not to allocate any land units at all to environment-friendly practices and to instead free-ride on others in order to earn the collective benefits. But the incentive payment solves the social dilemma since it compensates the opportunity cost of contributing to the public good. ${ }^{9}$ As shown in section 2.4, in the absence of 32 foreground risk (Benchmark and BackOnly treatments), farmers therefore allocate all their land units towards the environment-friendly farming practices $\left(\mathrm{g}_{\mathrm{i}}=\mathrm{L}_{\mathrm{i}}\right)$ in the payment scenario.

\footnotetext{
${ }^{9}$ This assumption is realistic since, in the current CAP, the payments associated with agri-environmental contracts are set-up to cover up the opportunity cost of adopting green practices. Concerning the green payment, while its level was not chosen to compensate the opportunity cost of adoption greening requirements, it has been shown that it is higher than the compliance costs for a large majority of farmers (Louhichi et al. 2018).
} 
1 In this game, farmers face strategic uncertainty because they don't know whether others will 2 contribute to the public good, even more so without pre-play communication. In all treatments, 3 strategic uncertainty is kept constant by keeping constant group size, anonymity in the group and 4 marginal incentives to contribute to the public good ( $\beta$ and $\delta$ ) as in Gangadharan and Nemes (2009). 5 In the experiment, we analyse decisions in a group of $n=2$ players. ${ }^{10}$

6 7

Table 1: parameters

\begin{tabular}{|c|c|c|c|c|c|c|c|c|}
\hline $\begin{array}{c}\text { Treatments } \\
\text { between- } \\
\text { subject }\end{array}$ & $\begin{array}{c}\text { Land } \\
\text { endowment } \\
L_{\mathrm{i}}^{11} \\
\text { (hectares) }\end{array}$ & $\begin{array}{l}\text { Financial } \\
\text { yield } \\
b \\
\text { (points/ } \\
\text { hectare) }\end{array}$ & $\begin{array}{c}\text { Cost of } \\
\text { conventional } \\
\text { practices } \\
c_{c} \\
\text { (points } \\
\text { /hectare) }\end{array}$ & $\begin{array}{c}\text { Cost of } \\
\text { green } \\
\text { practices } \\
c_{g} \\
\text { (points } \\
\text { /hectare) }\end{array}$ & $\begin{array}{l}\text { Efficiency } \\
\text { factor of the } \\
\text { green land } \\
\beta\left(g_{i}+\delta g_{-i}\right) \\
\text { (points } \\
\text { /hectare) }\end{array}$ & $\begin{array}{c}\text { No } \\
\text { payment } \\
\text { scenario }\end{array}$ & $\begin{array}{l}\text { Payment } \\
\text { scenario }\end{array}$ & $\begin{array}{c}\mathrm{Nb} \text { of } \\
\text { participants }\end{array}$ \\
\hline $\begin{array}{c}\text { Benchmark } \\
v_{a}=0 \\
v_{\varepsilon}=0\end{array}$ & 80 & 15 & 4 & 7 & $\begin{array}{l}\beta=2 \\
\delta=1\end{array}$ & $\mathrm{PAY}=0$ & $\mathrm{PAY}=2$ & 26 \\
\hline $\begin{array}{c}\text { ForeOnly } \\
v_{a}>0 \\
v_{\varepsilon}=0\end{array}$ & 80 & 15 & 4 & 5 or $9^{*}$ & $\begin{array}{l}\beta=2 \\
\delta=1\end{array}$ & $\mathrm{PAY}=0$ & $\mathrm{PAY}=2$ & 29 \\
\hline $\begin{array}{c}\text { BackOnly } \\
v_{a}=0 \\
v_{\varepsilon}>0\end{array}$ & 80 & 10 or $20^{*}$ & 4 & 7 & $\begin{array}{l}\beta=2 \\
\delta=1\end{array}$ & $\mathrm{PAY}=0$ & $\mathrm{PAY}=2$ & 39 \\
\hline $\begin{array}{c}\text { Fore\&Back } \\
v_{a}>0 \\
v_{\varepsilon}>0\end{array}$ & 80 & 10 or $20^{*}$ & 4 & 5 or $9^{*}$ & $\begin{array}{l}\beta=2 \\
\delta=1\end{array}$ & $\mathrm{PAY}=0$ & $\mathrm{PAY}=2$ & 30 \\
\hline
\end{tabular}

8 Note: *equally probable

\subsection{Experimental procedure}

10 The sample chosen for this experiment is made of full-time students in agriculture (for at least 2 11 years) of the Pays de la Loire region in France. While lab experiments with university students 12 remain common, a growing number of experiments involve samples of professionals. Gneezy and 13 Imas (2017) review evidence and conclude that it is important to elicit behaviour and preferences 14 with non-standard populations that are closer to the theoretically relevant target population. The 15 potential reasons for behavioural differences are the distribution of social preferences (Carpenter and 16 Seki 2011), familiarity of the subject with the topic (Frechette 2011) and self-selection issue. As

\footnotetext{
${ }^{10}$ While in reality the ecosystem services can benefit a larger perimeter where several farmers are operating, we have used the smallest possible group (2) to simplify the experiment. There is much literature on the effect of group size on contributions in public good games. For instance, Isaac et al. (1988) found no difference between groups of 4 and groups of 10 people. To our knowledge, there is no experimental evidence on the differences in the behaviours of individuals interacting in pairs (in a prisoners' dilemma) and in groups of 4 persons.

11 To reinforce the field context, we attempted to respect the same size as an average farm in the Pays de Loire region since most students come from the area. The average farm size in the area is 79.2 ha (Agreste 2017), so we chose 80 ha in our experiment.
} 
1 mentioned in the results section, the agricultural students we recruited have strong connections with

2 the farming environment, making them closer to stakeholders than other students.

3 The experiment was run in May 2017 and presented to students during one of their classes after 4 which they had 7 days to complete it on-line, with an exam question dedicated to the experiment. 5 The experiment was programmed with Limesurvey. Participants were randomly assigned by the software to one of the four treatments when they first logged-on.

At the beginning of the survey, participants were asked to read the instructions that explained the different parts of the survey and the monetary incentives. In each part of the survey, they answered

9 questions that tested their understanding of the instructions. Instructions are available in the appendix $10 \mathrm{C}$

11 The survey is divided into five parts. First, before the public good game, we have run two 12 complementary tasks to elicit risk aversion and social preferences. Risk aversion has been shown to 13 have a significant impact on decisions in public good games (Dickinson 1998), as well as in 14 coordination games. Social preferences are also important drivers of contributions in public good games (Fischbacher and Gachter 2010; Balliet, Parks and Joireman 2009).

16 The first part of the survey aims at eliciting risk attitudes. The game is a lottery-choice task derived 17 from the investment game (Gneezy and Potters 1997; Charness and Gneezy 2010). The higher the 18 number of points invested in the risky asset, the less risk averse is the participant. The relative 19 simplicity of the method makes it a useful instrument for assessing risk preferences in the field 20 (Charness, Gneezy and Imas 2013) and we believe it is also suitable for on-line elicitation.

21 In the second part, to measure social preferences, we have used the Social Value Orientation (SVO) measure (Murphy, Ackermann and Handgraaf 2011). Participants are asked to participate in a set of dictator games where they have to share some money with an anonymous player. Within the SVO framework, it is assumed that individuals have heterogeneous motivations when evaluating different resource allocations between themselves and another person. As examples, a decision maker may endeavour to maximize her own payoff (individualistic), maximize (competitive) or minimize (inequality averse) the difference between her own and the other person's payoff, or maximize joint payoffs (prosocial).

The public good game is played in the third (no payment) and fourth (with payment) parts of the experiment. Participants do not choose between a public and a private account (as in artefactual public good games), rather they divide their land between "green farming" and "conventional

32 farming". We rely on a contextualized experiment because we believe that the experimental context can trigger signals, such as pro-social, pro-environmental or context-specific risk preferences, that have an effect on the decision-making process under study. Environmental factors and the culture in which individuals develop, as well as prior experience shape preferences and have a critical influence on how individuals interact (Gneezy and Imas 2017).

37 We have chosen a "one-shot" design, which is different from most public goods experiments, where 38 participants make repeated decisions in a single treatment and receive feedback between rounds. It 
1 allows an asynchronous experimental design, which lessens the constraint on the number of 2 participants connected at the same time. Moreover, as explained by Goeree et al (2002), the one-shot 3 design mitigates the possibility of reciprocity or strategic attempts to trigger others' reciprocity. 4 Given the focus of the experiment on the impact of risk on the adoption of practices with public good 5 properties, we did not want good or bad experiences with respect to others' contribution to the public good to influence the game.

7 Before making their decision, participants could see two tables explaining their individual payoff 8 (depending on the number of land units allocated to environment-friendly practices by the 9 participant, as well as the random $\left.\operatorname{draw}(\mathrm{s})^{12}\right)$ and the additional group payoff (depending on the total 10 number of land units allocated to environment-friendly practices in their group). They were told that 11 their total payoff is the sum of the individual and the additional group payoff.

12 In the last part, qualitative and quantitative information was collected from the participants using 13 survey questions. In particular, we asked participants to state what would be the main reason for non14 adoption and the main lever likely to favour their adoption if they were a farmer. All participants 15 were invited to answer these questions, whether they adopted these practices or not in the 16 experiment.

17 Participants were informed that their decisions would affect the size of the earnings they would 18 receive. Points earned in each part ( 1 to 4 ) of the game are summed and converted at a known fixed 19 rate into euros (200 points=1 euro). At the end of the experiment, in order to calculate the final 20 earnings, all participants were randomly matched in pairs and the computer carried out random draws. A multi-brand gift card was sent to each participant via ordinary mail with a credit corresponding to the winnings in the survey. Final earnings were thus between 9 and $23 €$, with an average around $16 €$. It took on average 30 minutes to complete the survey.

\section{Experimental results}

\subsection{Our sample: descriptive statistics}

26124 agricultural students took part in the experiment. The participants were on average 20 years old and $54 \%$ were male. The following numbers indicate that they are concerned with agriculture and can be considered as stakeholders. $58 \%$ of them have farmers in their closest family members (parents, siblings or parental siblings). $44 \%$ of them spend more than 30 days a year on a farm. $30 \%$ of them declare they will be farmers before their thirties, and $40 \%$ do not reject this option. Less than one third of the participants already know they do not want to become farmers in the future.

32 No significant differences were observed in the socio-demographic characteristics, risk aversion and 33 social preferences in the four treatment groups, suggesting that random allocation of participants to 34 the different treatments had the desired effect.

\footnotetext{
${ }^{12}$ In treatments ForeOnly and BackOnly, the table with the individual payoff had 2 lines corresponding to the two possible outcomes of the draw. While in treatment Fore\&Back, the table had 4 lines, corresponding to the four different outcomes combining the two draws.
} 
1 Concerning social preferences, adapting Murphy et al.'s procedure (2011), we classify the 2 participants in two categories: the pro-social players (47\%), who aim at maximizing the joint payoff 3 of both players or at minimizing inequalities, and the other players (competitive and individualistic) $4 \quad(53 \%)$. With respect to risk aversion, we find that participants are willing to invest $43.4 \%$ of their 5 endowment in the risky option, slightly less than results of previous experiments (Charness and Gneezy 2012). No participants invested all their endowment in the risky asset, they are therefore all risk averse according to this elicitation method. Participants who invested fewer points in the risky asset are considered as more risk averse. Moreover, we checked that our results are not impacted by potential communication between the participants given that six and half days passed between the connection of the first participant and the last one. Indeed, one could argue that experiments conducted on-line lack control compared to lab experiments, in particular because once the experiment has begun, it is more difficult to control information flow about the task (Harrison and List 2004), especially given that participants know each other. To measure whether our results are impacted by this effect, we have verified that the submission date and the time dedicated to answering the survey (mean: 29 minutes, s.d: 16.5) are not significantly different across treatments (Kruskal-Wallis equality-of-populations rank test: Chi2(3) $=2.88$ and $\mathrm{p}=0.4105$ ).

On average over all treatment groups, the average number of hectares farmed according to environment-friendly farming is positive and equals to 50.64 ha (over a total of 80 ha). $95 \%$ of the participants allocated at least 20 hectares to the green practices in the no payment scenario. Our data thus suggest that most participants depart from payoff-maximization and voluntary contribute to environment-friendly farming, potentially due to their pro-environmental or pro-social preferences. This is consistent with previous experimental literature that has shown that individuals contribute on average more to the public good than predicted by the Nash equilibrium (see for instance Ledyard (1995) for a review on public good games). In our experiment, this is true in all treatments (Figure $1)$.

Figure 1: Average number of hectares cultivated with environment-friendly practices per treatment

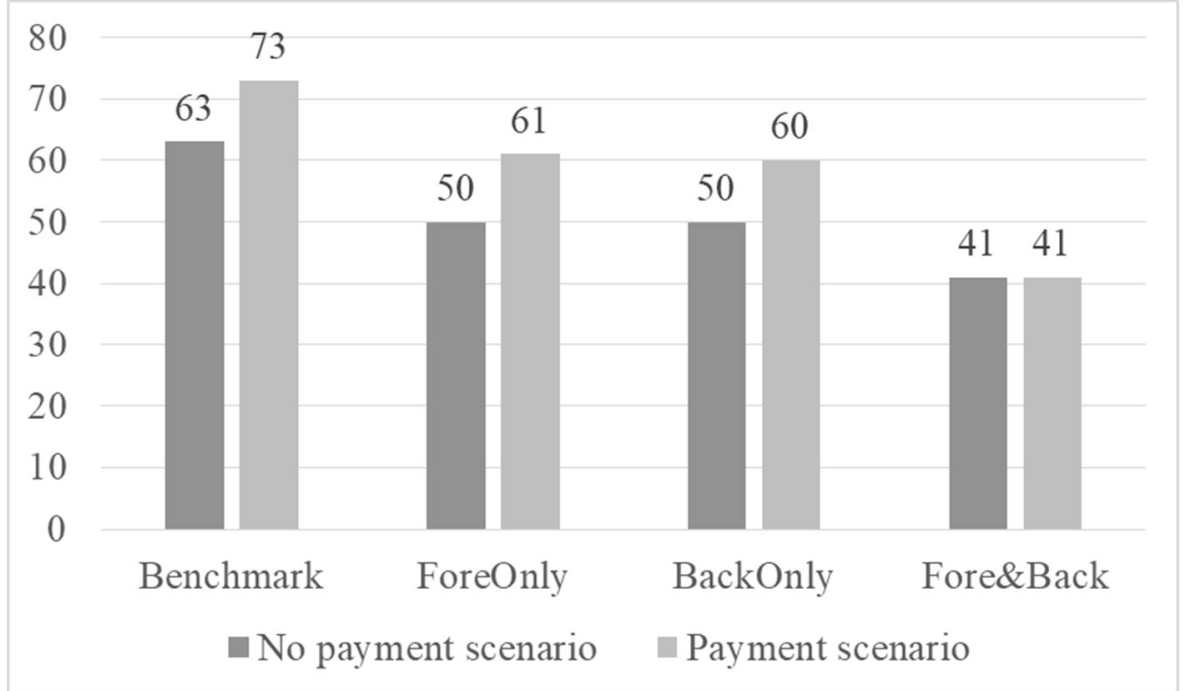




\subsection{Discussion of the empirical validity of the theoretical propositions}

2 Results are structured in order to shed light on the empirical validity of the three propositions drawn

3 from the theoretical model. First, we examine the differences across treatments in the number of

4 hectares farmed with environment-friendly practices using nonparametric tests (results are presented

5 in the appendix B). Second, we use an econometrical analysis to find out what motivated decisions.

6 The dependant variable is the number of hectares farmed with environment-friendly practices. We

7 rely on a random effect panel tobit model to account for the nature of the data (the number of

8 hectares are left-censored at zero and right-censored at 80 ). We use random effects at the subject

9 level to capture the unobserved heterogeneity between participants. ${ }^{13}$ The variables are described in

10 Table 2 and the results are shown in Table 3.

\section{Impact of foreground risk on the adoption of green practices (comparison Benchmark-}

12 ForeOnly).

13 In the presence of foreground risk, participants allocated less hectares to the environment-friendly

14 practices than those in the benchmark treatment (variable ForeOnly in Table 3 and non-parametric

15 tests in the appendix B). This result confirms proposition 1 of the theoretical model. It is consistent

16 with the fact that all participants are averse to (foreground) risk according to our elicitation method.

17 We confirm a well-known result in the agricultural empirical literature: risk-increasing environment-

18 friendly practices are less adopted than non-risky practices (Babcock, Fraser and Lekakis 2003; Acs

19 et al. 2009).

20 Impact of background risk on the adoption of green practices (comparison Benchmark-

21 BackOnly and ForeOnly-Fore\&Back).

22 Participants allocated less hectares to the environment-friendly practices in the presence of both

23 foreground and background risks than in the treatment with only foreground risk (variable

24 Fore\&Back and ForeOnly in Table 3 and non-parametric tests in the appendix B). This suggests that 25 participants take less risk (by reducing their commitment to risk-increasing environment-friendly

26 practices) in the presence of background risk, as stated by the risk vulnerability conjecture

27 (Eeckhoudt et al. 1996; Gollier and Pratt 1996). ${ }^{14}$

28 The model predicts that the background risk does not impact the allocation of land to green farming 29 in the absence of foreground risk. However, in the experiment, we observe that, even when 30 environment-friendly practices are not risky, participants allocate less hectares to these practices 31 when there is background risk than when there is none (BackOnly vs. Benchmark). This result cannot be explained by our theoretical model. It suggests that background risk can reduce the

\footnotetext{
${ }^{13}$ The main advantage of using random effects over fixed effects estimations is that it allows for covariates that are constant over time, such as the individual characteristics of the participants (Demidenko 2005).

${ }^{14}$ Moreover, according to proposition 3 (see appendix A3), the contribution to environment-friendly practices decreases when the covariance between both risks increases. We could therefore assume that the reduction of the contribution to environment-friendly practices in the treatment Fore\&Back would be even more pronounced if the experiment had been designed with positively correlated risks.
} 
1 willingness to contribute to a public good, a question that remains to be explored both empirically 2 and theoretically.

3 Proposition 2 is therefore only partially verified: background risk reduces the adoption of

4 environment-friendly practices, whether they are risky or not.

\section{Impact of the incentive payment (comparison "no payment"- "with payment")}

6 We have introduced interaction terms between the payment variable and the treatment variables in

7 the econometric model to further analyse the impact of the subsidy in the various risk scenarios

8 (PAY*treatment in Table 3). The model predicts that the incentive payment increases adoption of

9 environment-friendly practices in all risk contexts (proposition 4). It is only partially verified with

10 the experimental results: participants allocated significantly more hectares to the environment-

11 friendly practices in the payment scenario than in the absence of incentive payment in all treatments

12 but Fore\&Back. Indeed, the interaction term is significant only in Fore\&Back ( -24.05 ha farmed with

13 environment-friendly practices) and nearly cancels the average impact of the payment (+29.36 ha),

14 leading to a very small impact of the subsidy when both risks are present $(+5.31 \mathrm{ha})$.

15

16 Table 2: Summary of the dependant variables used in Table 3

\begin{tabular}{|c|c|c|}
\hline Name of the variable & Description & Statistics \\
\hline $\begin{array}{l}\text { Benchmark } \\
\text { ForeOnly } \\
\text { BackOnly } \\
\text { Fore\&Back }\end{array}$ & $\begin{array}{l}\text { Between-subject treatment variables } \\
1 \text { if the subject is assigned to the treatment with no risk } \\
\text { (Benchmark), foreground risk only (ForeOnly), background } \\
\text { risk only (BackOnly) and both types of risks (Fore\&Back). }\end{array}$ & \\
\hline PAY & $\begin{array}{l}\text { Within-subject treatment variable } \\
1 \text { if there is an incentive payment, } 0 \text { otherwise }\end{array}$ & \\
\hline $\begin{array}{l}\text { PAY * Benchmark } \\
\text { (and other treatments) }\end{array}$ & $\begin{array}{l}\text { Interaction term between treatment variables and the } \\
\text { payment variable } P A Y\end{array}$ & \\
\hline prosocial & $\begin{array}{l}1 \text { if the subject is prosocial according to the social value } \\
\text { orientation measure, } 0 \text { otherwise }\end{array}$ & $\begin{array}{l}0: 53 \% \\
1: 47 \%\end{array}$ \\
\hline PAY * prosocial & Interaction term between the dummies prosocial and $P A Y$ & \\
\hline risk aversion & $\begin{array}{l}\text { Number of point not invested in the risky asset in the risk } \\
\text { aversion elicitation task (between } 0 \text { and 500). The lower the } \\
\text { number of points invested, the more risk averse is the } \\
\text { participant. }\end{array}$ & $\begin{array}{l}\text { mean: } 282 \\
\text { sd: } 80\end{array}$ \\
\hline install_family & $\begin{array}{l}1 \text { if the participant plans to become a farmer and has } \\
\text { farmers in his/her family (father, mother, siblings, uncle, } \\
\text { ant), } 0 \text { otherwise }\end{array}$ & $\begin{array}{l}0: 73 \% \\
1: 27 \%\end{array}$ \\
\hline install_nofamily & $\begin{array}{l}1 \text { if the participant plans to become a farmer and has no } \\
\text { farmers in his/her family (father, mother, siblings, uncle, } \\
\text { ant), } 0 \text { otherwise }\end{array}$ & $\begin{array}{l}0: 96 \% \\
1: 4 \%\end{array}$ \\
\hline impact_envt & $\begin{array}{l}1 \text { if the subject thinks agricultural practices have a very } \\
\text { negative/rather negative/rather positive/very positive impact } \\
\text { on the environment, } 0 \text { otherwise }\end{array}$ & $\begin{array}{l}\text { Very negative: } 9 \% \\
\text { (reference) } \\
\text { Rather negative: } 65 \% \\
\text { Rather positive: } 24 \% \\
\text { Very positive: } 2 \%\end{array}$ \\
\hline
\end{tabular}


1 Table 3: Results of the regression models (coefficient and statistical significance, random effects

2 panel tobit)

\begin{tabular}{|c|c|c|c|}
\hline VARIABLES & $\begin{array}{c}\text { number of } \\
\text { hectares farmed } \\
\text { with } \\
\text { environment- } \\
\text { friendly } \\
\text { practices } \\
\end{array}$ & sigma_u & sigma_e \\
\hline ForeOnly & $\begin{array}{c}-18.47 * * \\
(8.856)\end{array}$ & & \\
\hline BackOnly & $\begin{array}{c}-19.87 * * \\
(8.313)\end{array}$ & & \\
\hline Fore\&Back & $\begin{array}{c}-32.69 * * * \\
(8.772)\end{array}$ & & \\
\hline PAY & $\begin{array}{c}29.36 * * * \\
(8.418)\end{array}$ & & \\
\hline PAY * ForeOnly & $\begin{array}{l}-9.489 \\
(10.21)\end{array}$ & & \\
\hline PAY * BackOnly & $\begin{array}{l}-7.603 \\
(9.641)\end{array}$ & & \\
\hline PAY * Fore $\&$ Back & $\begin{array}{c}-24.05 * * \\
(10.02)\end{array}$ & & \\
\hline Prosocial & $\begin{array}{l}14.68^{* *} \\
(5.826)\end{array}$ & & \\
\hline PAY * prosocial & $\begin{array}{l}-10.95^{*} \\
(6.303)\end{array}$ & & \\
\hline risk aversion & $\begin{array}{l}-0.0134 \\
(0.0326)\end{array}$ & & \\
\hline install_nofamily & $\begin{array}{c}43.93 * * * \\
(16.12)\end{array}$ & & \\
\hline install_family & $\begin{array}{c}1.795 \\
(5.881)\end{array}$ & & \\
\hline impact_envt_negative & $\begin{array}{l}-7.686 \\
(9.466)\end{array}$ & & \\
\hline impact_envt_positive & $\begin{array}{l}-6.917 \\
(10.64)\end{array}$ & & \\
\hline impact_envt_verypositive & $\begin{array}{l}-35.86 * * \\
(17.82)\end{array}$ & & \\
\hline Constant & $\begin{array}{c}75.85 * * * \\
(14.17) \\
\end{array}$ & $\begin{array}{c}20.55 * * * \\
(2.715) \\
\end{array}$ & $\begin{array}{c}22.31 * * * \\
(1.782) \\
\end{array}$ \\
\hline Observations & 248 & & \\
\hline Number of id & 124 & & \\
\hline Rho & $\begin{array}{ll}0.459 & 0.083\end{array}$ & & \\
\hline Log likelihood & -812.032 & & \\
\hline Wald chi2(14) & 67.15 & & \\
\hline Prob $>$ chi 2 & 0.00 & & \\
\hline
\end{tabular}

Note: 10 left-censored observations, 155 uncensored observations, 83 right-censored observations. The regression coefficients are relative to the benchmark treatment and no payment scenario. The Chi2 values provide evidence of the models' explanatory power. Standard errors are in parentheses beneath coefficient estimates. The number of stars indicates the significance level: $* * *$ is significant at $1 \%, * *$ is significant at $5 \%, *$ is significant at $10 \%$. 
2 Besides treatment effects, the random effect tobit results allow to comment on the impact of other

3 variables collected in the on-line survey. Controlling for these socio-demographic and attitudinal

4 factors in the experiment offers a useful complement to the theoretical model, where the structure of

5 preferences is simplified.

6 A decision-maker's risk attitude is often considered as essential for explaining and forecasting farm 7 management behavior (Vollmer, Hermann and Mußhoff 2017). However, here, risk aversion as elicited in the simple portfolio investment game does not seem to explain decisions to farm with 9 risky environment-friendly practices (risk aversion variable in Table 3), and this is true in all 10 treatments (model with interaction terms not presented here). This result is consistent with 11 Gangadharan and Nemes (2009), who did not find either that elicited risk aversion provides a 12 consistent pattern of behaviour in their public good game with uncertainty. The use of behavioural 13 elicitation method for risk preferences has recently been challenged in the literature. Despite their 14 widespread use in the lab, these methods are unproven for predicting real world farming behaviour 15 (Hellerstein, Higgins and Horowitz 2013). Moreover, several authors have shown that risk 16 preferences are not stable across elicitation methods (Pedroni et al. 2017; Reynaud and Couture 17 2012; Brunette et al. 2015; Deck et al. 2013; Soane and Chmiel 2005; Crosetto and Filippin 2016; 18 Deck, Lee and Reyes 2014; Weber, Blais and Betz 2002; Dave et al. 2010). In particular, Dave et al. 19 (2010) show that the simplest measure (such as the one we used) have an inferior predictive accuracy. Choosing a lottery-choice measure of risk preferences therefore implies a trade-off between the cognitive burden for the respondents and the predictive performance. We thus cannot disregard the hypothesis that the investment game task we chose provides an unreliable measure of participants' risk aversion.

We observe a significant impact of social value orientation, as defined by Murphy et al. (2011), on decisions: pro-social individuals are more willing to farm with environment-friendly practices than the others. We also observe a negative and significant impact of the interaction term between payment and pro-social individuals, suggesting that the incentive is more effective in changing nonpro-social individual behaviours (as in, for example, Midler et al. 2015). Still, it increases cooperation even among pro-social individuals. Previous studies have documented the impact of farmers' environmental attitude on the adoption of environment-friendly practices and on the acceptance rate of agri-environmental policies (Beedell and Rehman 2000; Vanslembrouck, Huylenbroeck and Verbeke 2002; Willock et al. 1999). Here, we found that participants who think that agricultural practices have a very positive impact on the environment farmed significantly less hectares with environment-friendly practices in the experiment. We think that those answers can reflect a form of disagreement with the experiment postulate that some agricultural practices are not environment-friendly. It could illustrate that some farmers are still not convinced about the need to change practices since they believe conventional practices are not harmful. It could also be that participants perceive the payment instrument as an attempt by the administration to control 
1 individual decision (Thomas et al. 2019). The participants with such beliefs are not willing to bear

2 the extra cost and risk of more environment-friendly practices in the experiment.

3 Plans for the future are important explanatory factors of the agricultural students' decisions in the 4 game. $80 \%$ of those who plan to become a farmer but have no farmers in their family declare they 5 are willing to set-up an organic farm (while only $30 \%$ of those planning to set-up as a farmer within the family context plan to do so). They are also more likely to farm with environment-friendly practices in the game, compared to those who do not plan to become farmers (variable install_nofamily significant). This is not the case for those who plan to set-up within the family context (variable install_family not significant). This result is in line with what has been observed in

10 France: new farmers that are not taking over their parents' agricultural holding are more likely to 11 engage in organic farming (Ambiaud 2011).

\section{5. Discussion}

13 We discuss here the contributions and limitations of this study, suggestions for future research and 14 the policy implications of our results.

15 In order to understand the impact of background risk (such as climate change) on the adoption of environment-friendly practices, often perceived as risk-increasing, we have developed a theoretical model and designed a public good experiment that combined background and foreground risks. To our knowledge, we are the first to study how background risk influences the contributions to a public good game, in particular when it is combined with foreground risk.

Based on a two-moment decision model, we have found that background risk reduces the adoption of risky environment-friendly practices. We have also demonstrated that an incentive payment per hectare of land farmed with environment-friendly practices encourages the adoption of such practices in a risky context with foreground or background risk. Furthermore, an experiment has allowed to test these theoretical propositions, but also to go further: we find that background risk such as climate change can reduce the willingness to engage in environment-friendly practices with public good properties, even if they are not risk-increasing. We also find that an incentive payment designed to solve the social dilemma is not sufficient in the presence of both foreground and background risks: players do not allocate significantly more land to green practices when they receive the payment.

The main limitations of our study are due to the necessary simplification of reality in a model or an experiment. First, the risk setting is over simplified. For example, in the theoretical model, we do not take into account the preferences for skewness and kurtosis, while there is empirical evidence on the importance of downside risk for farmers (Kim et al. 2014; Zuo, Nauges and Wheeler 2015). Moreover, while the model does, the experimental design did not allow to test the impact of the correlation between the foreground and the background risks. Improving the methods used to elicit individual risk preferences could also allow to better distinguish the role of risk aversion and risk vulnerability from the influence of the treatment variables. 
1 Second, in the experiment, the choice of parameters fails to capture the heterogeneity in farming 2 contexts and green agricultural practices. Further research could focus on testing whether our results 3 are robust to a change in the average value and standard deviation of the costs and benefits 4 parameters, which could be chosen in order to better represent a specific green practice and increase 5 the external validity. More experimental sessions would have also allowed to run some sensitivity analysis on the impact of farm size (impacting the size of the background risk) and the impact of the 7 payment size.

8 Despite these limitations, the results shed light on existing agricultural policies. In the actual 9 European agricultural context, both protecting the environment and managing uncertainties are issues 10 that are gaining importance (European Commission 2017). However, CAP support to sustainable 11 agriculture and risk management are mostly discussed separately so far and targeted by different 12 policy instruments. Our results suggest that instruments aiming at motivating farmers to better 13 manage the environment should take into account not only the risk associated with the adoption of 14 more environment-friendly practices, but also the background risk. Indeed, it is often argued that 15 CAP incentives set-up as a fixed amount per hectare received regardless of the market conditions, 16 such as agri-environmental measures, could improve environment-friendly practices adoption by 17 covering the extra cost and the foregone revenues (including the risk premium). Yet, in our 18 experiment, such fixed payments appeared to be less efficient in the presence of both foreground and 19 background risk. This questions the efficiency of agri-environmental payments, set-up as a fixed 20 subsidy per hectare, in the presence of multiple risk sources such as pest attacks, climate hazards, 21 price volatility and climate change.

22 One response could be to increase the payment for adoption of environment-friendly practices in 23 highly risky environment. It might make the payments more effective in triggering adoption but it 24 has two limits: first, it might be difficult to do because the amount must comply with the WTO rules and cannot exceed the foreseen costs of changing practices. This rule prevents management authorities to sufficiently increase the payment level to integrate the cost of risk in their payments. Second, it might be less cost-effective than other risk management tools.

28 In the CAP 2020 proposal, the European Commission proposes to make risk management tools mandatory for all member states (European Commission 2017). These tools, which include insurance, mutual funds, saving accounts, ad-hoc payments and fiscal measures, were already available in the previous CAP under pillar II, but implemented by member states on a voluntary basis. As a result, the share of CAP funds being spent on crisis and prevention measures remained very low (Bardaji and Garrido 2016). Our results suggest that such instruments, which are helping farmers manage background risk, could also impact positively their willingness to adopt green practices. Making them mandatory could thus generate environmental co-benefits, if they are not financed using the agri-environmental instruments funding.

37 Building bridges between environmental objectives and risk management by proposing risk 38 management tools to farmers that are conditional on the transition towards more sustainable practices 39 could foster the adoption of riskier and more costly green practices while helping farmers 
1 maintaining a safe level of income (Huang 2002; Coble et al. 2003). The experience "Fondo 2 Risemina Mais" (Veneto, Italy) is one of the very few experiments in Europe of an agricultural3 environmental insurance (PANEurope n.d.). In this program, farmers are offered a crop insurance 4 financed by a mutual fund in case of pest damage to maize, as well as damage due to adverse 5 weather conditions; and in return they agree to comply with good agricultural practices and integrated pest management. The payment is therefore not systematic, but triggered in case of unfavorable local climatic conditions or pest attacks. To our best knowledge, this scheme has not been evaluated yet. There is scope for an experimental study to analyze the impact of such an instrument on the adoption of environment-friendly practices given the numerous behavioral factors likely to influence the perceived value of such an insurance by farmers (Coble et al. 2003; Chèze et al. 2020). Ignoring these factors may lead to error when predicting participation.

\section{Conclusion}

14 The critical impact of uncertainty on the adoption of environment-friendly practices has not fully been explored yet: the analysis has been restricted to the impact of foreground risk. However, while farmers can choose to avoid the uncertainty associated with environment-friendly practices by farming their land with well-established and less risky practices, they are also exposed to background risks beyond their control. Considering climate change is a major source of background risk in the agricultural sector, it is important to take it into account to improve our understanding of farmers' risk taking decisions. Using a theoretical model and a framed lab experiment with 124 French agricultural students based on a public good game, we have analysed the combined impact of foreground and background risk on decisions to adopt environment-friendly practices and evaluated how incentive payments may influence adoption decisions in such a risky environment.

We observe that adopting green farming practices is less likely when they are risky. More interestingly, we show that background risk is also detrimental to the adoption of green farming practices, suggesting that participants are both risk averse and risk vulnerable. While the theoretical literature is silent on this point, we find that background risk can reduce the willingness to engage in environment-friendly practices with public good properties, even if there are not risk-increasing. Moreover, we highlight that a given incentive payment can efficiently increase the adoption of green practices when only one source of risk exist but can fail to do so in the presence of both foreground and background risks. In terms of policy implications, our research demonstrates the limited efficiency of a fixed payment per hectare (such as agri-environmental payment) to encourage the adoption of risky environment-friendly practices in the presence of background risk. More generally, our results suggest the importance of building bridges between environmental objectives and risk management in the CAP, for example by proposing risk management tools to farmers that are conditional on the transition towards more sustainable systems. 


\section{References}

Acemoglu, D., and M.K. Jensen. 2013. "Aggregate comparative statics." Games and Economic Behavior 81:27-49.

Acs, S., P. Berentsen, R. Huirne, and M. Asseldonk. 2009. "Effect of yield and price risk on conversion from conventional to organic farming *." Australian Journal of Agricultural and Resource Economics 53:393-411.

Agreste. 2017. "Mémento de la statistique agricole Pays de Loire." Available at: http://agreste.agriculture.gouv.fr/IMG/pdf/R5217C02.pdf.

Ambiaud, E. 2011. "Diversité du monde agricole." Available at: http://agreste.agriculture.gouv.fr/IMG/pdf_analyse321106.pdf.

Babcock, B.A., R.W. Fraser, and J.N. Lekakis. 2003. "Risk Management and the Environment in Agriculture: A Key Policy Theme.” In B. A. Babcock, R. W. Fraser, and J. N. Lekakis, eds. Risk Management and the Environment: Agriculture in Perspective. Dordrecht: Springer Netherlands, pp. 1-8. Available at: https://doi.org/10.1007/978-94-017-2915-4_1 [Accessed September 24, 2019].

Balliet, D., C. Parks, and J. Joireman. 2009. "Social Value Orientation and Cooperation in Social Dilemmas: A Meta-Analysis.” Group Processes \& Intergroup Relations 12(4):533-547.

Bardaji, I., and A. Garrido. 2016. "Research for AGRI Committee - State of Play of Risk Management Tools Implemented by Member States During the Period 2014-2020: National and European Aramework." Available at: http://www.europarl.europa.eu/RegData/etudes/STUD/2016/573415/IPOL_STU(2016)57341 5 EN.pdf.

Bazoche, P., F. Bunte, P. Combris, E. Giraud-Héraud, A. Seabra-Pinto, and E. Tsakiridou. 2013. "Willingness to pay for pesticides'reduction in EU: nothing but organic?" European review of Agricultural Economics 41(1):87-109.

Bchir, M.A., and M. Willinger. 2013. "Does the exposure to natural hazards affect risk and time preferences? Some insights from a field experiment in Perú." LAMETA, Universitiy of Montpellier. Available at: https://econpapers.repec.org/paper/lamwpaper/13-04.htm

Beaud, M., and M. Willinger. 2014. “Are People Risk Vulnerable?" Management Science 61(3):624-636.

Beedell, J., and T. Rehman. 2000. "Using social-psychology models to understand farmers' conservation behaviour." Journal of Rural Studies 16(1):117-127.

Binswanger, H.P. 1980. "Attitudes Toward Risk: Experimental Measurement in Rural India." American Journal of Agricultural Economics 62(3):395-407.

Bocquého, G., F. Jacquet, and A. Reynaud. 2014. "Expected utility or prospect theory maximisers? Assessing farmers' risk behaviour from field-experiment data." European Review of Agricultural Economics 41(1):135-172.

Bontems, P., and C. Nauges. 2019. "Production choices with water markets and risk aversion: the role of initial allocations and forward trading." European Review of Agricultural Economics 46(4):579-608.

Bougherara, D., X. Gassmann, L. Piet, and A. Reynaud. 2017. "Structural estimation of farmers' risk and ambiguity preferences: a field experiment." European Review of Agricultural Economics 44(5):782-808. 
Brunette, M., J. Choumert, S. Couture, and C. Montagne-Huck. 2015. "A Meta-analysis of the Risk Aversion Coefficients of Natural Resource Managers Evaluated by Stated Preference Methods." Working Papers - Cahiers du LEF No. 2015-13, Laboratoire d'Economie Forestiere, AgroParisTech-INRA. Available at: https://ideas.repec.org/p/lef/wpaper/201513.html

Carpenter, J., and E. Seki. 2011. "Do Social Preferences Increase Productivity? Field Experimental Evidence from Fishermen in Toyama Bay.” Economic Inquiry 49(2):612-630.

Charness, G., and U. Gneezy. 2010. "Portfolio Choice and Risk Attitudes: An Experiment." Economic Inquiry 48(1):133-146.

Charness, G., and U. Gneezy. 2012. "Strong Evidence for Gender Differences in Risk Taking." Journal of Economic Behavior \& Organization 83(1):50-58.

Charness, G., U. Gneezy, and A. Imas. 2013. "Experimental methods: Eliciting risk preferences." Journal of Economic Behavior \& Organization 87:43-51.

Chavas, J.-P., and M.T. Holt. 1996. "Economic Behavior Under Uncertainty: A Joint Analysis of Risk Preferences and Technology." The Review of Economics and Statistics 78(2):329-335.

Chèze, B., M. David, and V. Martinet. 2020. "Understanding farmers' reluctance to reduce pesticide use: A choice experiment." Ecological Economics 167:106349.

Coble, K.H., T. Hanson, J.C. Miller, and S. Shaik. 2003. "Agricultural Insurance as an Environmental Policy Tool.” Journal of Agricultural and Applied Economics 35(2):391-405.

Coyle, B.T. 1999. "Risk Aversion and Yield Uncertainty in Duality Models of Production: A MeanVariance Approach.” American Journal of Agricultural Economics 81(3):553-567.

Crosetto, P., and A. Filippin. 2016. "A theoretical and experimental appraisal of four risk elicitation methods.” Experimental Economics 19:613-641.

Dave, C., C. Eckel, C. Johnson, and C. Rojas. 2010. "Eliciting Risk Preferences: When Is Simple Better?" Journal of Risk and Uncertainty 41:219-243.

Deck, C., J. Lee, and J. Reyes. 2014. "Investing versus gambling: experimental evidence of multidomain risk attitudes." Applied Economics Letters 21(1):19-23.

Deck, C., J. Lee, J.A. Reyes, and C.C. Rosen. 2013. "A failed attempt to explain within subject variation in risk taking behavior using domain specific risk attitudes." Journal of Economic Behavior \& Organization 87:1-24.

Demidenko, E. 2005. "Introduction: Why Mixed Models?" In Mixed Models. John Wiley \& Sons, Ltd, pp. 1-44. Available at: https://onlinelibrary.wiley.com/doi/abs/10.1002/0471728438.ch1

Diamond, D.W. 1984. "Financial Intermediation and Delegated Monitoring." The Review of Economic Studies 51(3):393-414.

Dickinson, D.L. 1998. "The voluntary contributions mechanism with uncertain group payoffs." Journal of Economic Behavior \& Organization 35(4):517-533.

Dorward, A. 1999. "Modelling embedded risk in peasant agriculture: methodological insights from northern Malawi." Agricultural Economics 21(2):191-203.

Ducos, G., P. Dupraz, and F. Bonnieux. 2009. "Agri-environment contract adoption under fixed and variable compliance costs." Journal of Environmental Planning and Management 52(5):669687. 
Eeckhoudt, L., C. Gollier, and H. Schlesinger. 1996. "Changes in Background Risk and Risk Taking Behavior." Econometrica 64(3):683-689.

3 Eichner, T. 2008. "Mean Variance Vulnerability.” Management Science 54(3):586-593.

Eichner, T., and A. Wagener. 2011. "Increases in skewness and three-moment preferences." Mathematical Social Sciences 61(2):109-113.

Espinosa-Goded, M., J. Barreiro-Hurlé, and P. Dupraz. 2013. "Identifying additional barriers in the adoption of agri-environmental schemes: The role of fixed costs." Land Use Policy 31:526535.

European Commission. 2017a. "The Future of Food and Farming." Available at: https://ec.europa.eu/agriculture/sites/agriculture/files/future-ofcap/future_of_food_and_farming_communication_en.pdf.

European Commission. 2017b. "The future of food and farming." Available at: https://ec.europa.eu/agriculture/sites/agriculture/files/future-ofcap/future_of_food_and_farming_communication_en.pdf.

Fischbacher, U., and S. Gachter. 2010. "Social Preferences, Beliefs, and the Dynamics of Free Riding in Public Goods Experiments." American Economic Review 100(1):541-556.

Frechette, G.R. 2011. “Laboratory Experiments: Professionals Versus Students.” No. ID 1939219, Social Science Research Network. Available at: https://papers.ssrn.com/abstract=1939219

Gangadharan, L., and V. Nemes. 2009. "Experimental Analysis of Risk and Uncertainty in Provisioning Private and Public Goods." Economic Inquiry 47(1):146-164.

Gneezy, U., and A. Imas. 2017. "Chapter 10 - Lab in the Field: Measuring Preferences in the Wild." In A. V. Banerjee and E. Duflo, eds. Handbook of Economic Field Experiments. Handbook of Field Experiments. North-Holland, pp. 439-464. Available at: http://www.sciencedirect.com/science/article/pii/S2214658X16300058

Gneezy, U., and J. Potters. 1997. "An Experiment on Risk Taking and Evaluation Periods.” The Quarterly Journal of Economics 112(2):631-645.

Goeree, J.K., C.A. Holt, and S.K. Laury. 2002. "Private costs and public benefits: unraveling the effects of altruism and noisy behavior." Journal of Public Economics 83(2):255-276.

Gollier, C. 2001. The Economics of Risk and Time. MIT Press, Cambridge, Mass.

Gollier, C., and J.W. Pratt. 1996. "Risk Vulnerability and the Tempering Effect of Background Risk." Econometrica 64(5):1109-1123.

Guillou, M., H. Guyomard, C. Huyghe, and J.L. Peyraud. 2013. "Le projet agro-écologique: Vers des agricultures doublement performantes pour concilier compétitivité et respect de l'environnement." Available at: http://www.ladocumentationfrancaise.fr/var/storage/rapportspublics/134000352.pdf.

Hardaker, J.B., S. Pandey, and L.H. Patten eds. 1991. "Farm Planning under Uncertainty: A Review of Alternative Programming Models." Review of Marketing and Agricultural Economics.

Harrison, G.W., and J.A. List. 2004. "Field Experiments." Journal of Economic Literature 42(4):1009-1055.

Harrison, G.W., J.A. List, and C. Towe. 2007. "Naturally Occurring Preferences and Exogenous Laboratory Experiments: A Case Study of Risk Aversion." Econometrica 75(2):433-458. 
Hellerstein, D., N. Higgins, and J. Horowitz. 2013. "The predictive power of risk preference measures for farming decisions." European Review of Agricultural Economics 40(5):807833.

Herberich, D.H., and J.A. List. 2012. "Digging into Background Risk: Experiments with Farmers and Students." American Journal of Agricultural Economics 94(2):457-463.

Huang, W.-Y. 2002. "Using Insurance to Enhance Nitrogen Fertilizer Application Timing to Reduce Nitrogen Losses." Journal of Agricultural and Applied Economics 34(1):131-148.

Isaac, R.M., and J.M. Walker. 1988. "Group Size Effects in Public Goods Provision: The Voluntary Contributions Mechanism.” The Quarterly Journal of Economics 103(1):179-199.

Isik, M. 2002. "Resource Management under Production and Output Price Uncertainty: Implications for Environmental Policy." American Journal of Agricultural Economics 84(3):557-571.

Kim, K., J.-P. Chavas, B. Barham, and J. Foltz. 2014. "Rice, irrigation and downside risk: a quantile analysis of risk exposure and mitigation on Korean farms." European Review of Agricultural Economics 41(5):775-815.

Knapp, S., and M.G.A. van der Heijden. 2018. "A global meta-analysis of yield stability in organic and conservation agriculture." Nature Communications 9(1):3632.

Lechenet, M., F. Dessaint, G. Py, D. Makowski, and N. Munier-Jolain. 2017. "Reducing pesticide use while preserving crop productivity and profitability on arable farms." Nature Plants 3(3):nplants20178.

Ledyard, J.O. 1995. "Public Goods: A Survey of Experimental Research." In Handbook of Experimental Economics. J. Kagel and A. Roth, pp. 111-194.

Lee, J. 2008. "The effect of the background risk in a simple chance improving decision model." Journal of Risk and Uncertainty 36(1):19-41.

Lefebvre, M., J. Papaïx, G. Mollot, P. Deschodt, C. Lavigne, J.-M. Ricard, J.-F. Mandrin, and P. Franck. 2017. "Bayesian inferences of arthropod movements between hedgerows and orchards." Basic and Applied Ecology 21(Supplement C):76-84.

Levati, M.V., and A. Morone. 2013. "Voluntary Contributions with Risky and Uncertain Marginal Returns: The Importance of the Parameter Values." Journal of Public Economic Theory 15(5):736-744.

Levati, M.V., A. Morone, and A. Fiore. 2009. "Voluntary contributions with imperfect information: An experimental study." Public Choice 138(1-2):199-216.

Louhichi, K., P. Ciaian, M. Espinosa, A. Perni, and S. Gomez y Paloma. 2018. "Economic impacts of CAP greening: application of an EU-wide individual farm model for CAP analysis (IFMCAP).” European Review of Agricultural Economics 45(2):205-238.

Lusk, J.L., and K.H. Coble. 2008. "Risk aversion in the presence of background risk: Evidence from an economic experiment." In Risk Aversion in Experiments. Research in Experimental Economics. Emerald Group Publishing Limited, pp. 315-340. Available at: https://www.emeraldinsight.com/doi/abs/10.1016/S0193-2306\%2808\%2900006-9 [Accessed August 31, 2018].

Menapace, L., G. Colson, and R. Raffaelli. 2013. "Risk Aversion, Subjective Beliefs, and Farmer Risk Management Strategies.” American Journal of Agricultural Economics 95(2):384-389. 
Meyer, J. 1987. "Two-Moment Decision Models and Expected Utility Maximization." The American Economic Review 77(3):421-430.

Midler, E., U. Pascual, A.G. Drucker, U. Narloch, and J.L. Soto. 2015. "Unraveling the effects of payments for ecosystem services on motivations for collective action." Ecological Economics 120:394-405.

Moschini, G., and D.A. Hennessy. 2001. "Chapter 2 Uncertainty, risk aversion, and risk management for agricultural producers." In Handbook of Agricultural Economics. Agricultural Production. Elsevier, pp. 87-153. Available at: http://www.sciencedirect.com/science/article/pii/S1574007201100058

Murphy, R.O., K.A. Ackermann, and M. Handgraaf. 2011. "Measuring Social Value Orientation." SSRN Electronic Journal. Available at: http://www.ssrn.com/abstract=1804189 [Accessed July 20, 2017].

Narloch, U., U. Pascual, and A.G. Drucker. 2012. "Collective Action Dynamics under External Rewards: Experimental Insights from Andean Farming Communities." World Development 40(10):2096-2107.

OECD. 2009. "Managing Risk in Agriculture: a Holistic Approach." Available at: http://www.oecd.org/tad/agriculturalpolicies/managingriskinagricultureaholisticapproach.htm

PANEurope. "Inspiration note for the development of EU's Common Agricultural Policy: What changes are needed to make risk management tools a suitable rural development measure?" Available at: http://www.pan-europe.info/sites/paneurope.info/files/public/resources/briefings/pan-e-risk-management-tool.pdf.

Pedroni, A., R. Frey, A. Bruhin, G. Dutilh, R. Hertwig, and J. Rieskamp. 2017. "The risk elicitation puzzle." Nature Human Behaviour 1(11):803.

Quiggin, J. 2003. "Background risk in generalized expected utility theory." Economic Theory 22(3):607-611.

Reynaud, A., and S. Couture. 2012. "Stability of risk preference measures: results from a field experiment on French farmers." Theory and Decision 73(2):203-221.

Ridier, A., K. Chaib, and C. Roussy. 2016. "A Dynamic Stochastic Programming model of crop rotation choice to test the adoption of long rotation under price and production risks." European Journal of Operational Research 252(1):270-279.

Serra, T., D. Zilberman, B.K. Goodwin, and A. Featherstone. 2006. "Effects of decoupling on the mean and variability of output." European Review of Agricultural Economics 33(3):269-288.

Soane, E., and N. Chmiel. 2005. "Are risk preferences consistent?: The influence of decision domain and personality." Personality and Individual Differences 38(8):1781-1791.

Thomas, F., E. Midler, M. Lefebvre, and S. Engel. 2019. "Greening the common agricultural policy: a behavioural perspective and lab-in-the-field experiment in Germany." European Review of Agricultural Economics 46(3):367-392.

Vanslembrouck, I., G.V. Huylenbroeck, and W. Verbeke. 2002. "Determinants of the Willingness of Belgian Farmers to Participate in Agri-environmental Measures." Journal of Agricultural Economics 53(3):489-511. 
Vollmer, E., D. Hermann, and O. Mußhoff. 2017. "Is the risk attitude measured with the Holt and Laury task reflected in farmers' production risk?" European Review of Agricultural Economics 44(3):399-424.

Weber, E.U., A.-R. Blais, and N.E. Betz. 2002. "A domain-specific risk-attitude scale: measuring risk perceptions and risk behaviors." Journal of Behavioral Decision Making 15(4):263-290.

Willock, J., I.J. Deary, G. Edwards-Jones, G.J. Gibson, M.J. McGregor, A. Sutherland, J.B. Dent, O. Morgan, and R. Grieve. 1999. "The Role of Attitudes and Objectives in Farmer Decision Making: Business and Environmentally-Oriented Behaviour in Scotland." Journal of Agricultural Economics 50(2):286-303.

10 Zuo, A., C. Nauges, and S.A. Wheeler. 2015. "Farmers' exposure to risk and their temporary water trading." European Review of Agricultural Economics 42(1):1-24. 


\section{Appendix A: theoretical model}

2 Having laid down the foundations of the model in the text in section 2, we derive the results here.

3 We start by establishing the nature of the background risk in subsection A.1. In A.2, we characterize

4 the nature of the game by showing that there are strategic complementarities between decisions if

5 preferences are DARA. In A.3, we establish a number of comparative statics results.

\section{$6 \quad$ A.1 The nature of the background risk}

7 Let us first analyze in details the nature of the background risk. To do so, it is convenient to use the

8 size of land $L_{i}$ for upscaling since the background risk is proportional to it.

9 First, the background risk is fair because upscaling the risk always raises the expected wealth $10\left(\partial \mu / \partial L_{i}=\bar{\varepsilon}>0\right)$. Second, this background risk is actually a risk only if its upscaling never 11 decreases the variance of the final wealth (alternatively, one could say that the size $L_{i}$ is risk 12 increasing):

$$
\frac{\partial v}{\partial L_{i}}=2 v_{\varepsilon} L_{i}+2 g_{i} \sigma_{a \varepsilon} \geq 0
$$

14 which happens if and only if the size $L_{i}$ is large enough for a given choice $g_{i}$ :

$$
L_{i} \geq-g_{i} \frac{\sigma_{a \varepsilon}}{v_{\varepsilon}}
$$

16 Note that if $\sigma_{a \varepsilon}>0$ (positive correlation between $a$ and $\varepsilon$ ), this condition is always met and the size

$17 L_{i}$ is risk increasing. On the contrary, when the correlation between the foreground and the 18 background risk is negative, and given that the decision $g_{i}$ satisfies $g_{i} \leq L_{i}$, a sufficient condition for $19 L_{i}$ to be risk increasing is that $-\sigma_{a \varepsilon} \leq v_{\varepsilon}$.

20 Finally, the background risk is undesirable if its upscaling decreases utility $U$ :

$$
\frac{\partial U}{\partial L_{i}}=V_{\mu} \frac{\partial \mu}{\partial L_{i}}+V_{v} \frac{\partial v}{\partial L_{i}} \leq 0
$$

22 or equivalently:

$$
\frac{\partial v}{\partial L_{i}} \geq \frac{\bar{\varepsilon}}{\alpha}
$$

24 i.e. if and only if $L_{i}$ is sufficiently risk increasing. 


\section{A.2 The nature of the game}

2 To determine the nature of the game between farmers, we need to derive the marginal influence of 3 others' strategy on farmer's $i$ action. Let us derivate totally the first-order condition w.r.t. $g_{i}$ and $g_{-i}$

4 to determine the slope of the best-response function:

$$
\left(V_{\mu \mu} \frac{\partial \mu}{\partial g_{i}}+V_{\mu v} \frac{\partial v}{\partial g_{i}}\right) \frac{\partial \mu}{\partial g_{-i}} d g_{-i}+\frac{\partial^{2} U}{\partial g_{i}^{2}} d g_{i}=0
$$

6 recalling that $g_{-i}$ only intervenes in expected wealth of farmer $i$ (and not in its variance).

7 It follows that:

$$
\frac{d g_{i}}{d g_{-i}}=-\frac{\frac{\partial \mu}{\partial g_{-i}}}{\frac{\partial^{2} U}{\partial g_{i}^{2}}}\left(V_{\mu \mu} \frac{\partial \mu}{\partial g_{i}}+V_{\mu v} \frac{\partial v}{\partial g_{i}}\right)
$$

9 The sign of the slope is determined by the sign of the term brackets as $\frac{\partial^{2} U}{\partial g_{i}^{2}}<0$ because of second 10 order condition and $\frac{\partial \mu}{\partial g_{-i}}=\beta \delta \geq 0$. Recall now that $\frac{\partial \mu}{\partial g_{i}}>0$ and that the first-order condition also 11 imposes that $\frac{\partial v}{\partial g_{i}}>0$. Furthermore, $V_{\mu \mu}<0$ because of risk aversion and $V_{\mu v}>0$ because of 12 prudence. It follows that, in this case, the sign is a priori ambiguous. Nevertheless we can show that 13 at the equilibrium:

$$
V_{\mu \mu} \frac{\partial \mu}{\partial g_{i}}+V_{\mu v} \frac{\partial v}{\partial g_{i}}=\left(V_{\mu \mu} \alpha+V_{\mu v}\right) \frac{\partial v}{\partial g_{i}}
$$

15 and also that:

$$
\alpha_{\mu}=-\frac{V_{\mu \mu} \alpha+V_{\mu v}}{V_{\mu}}<0(D A R A)
$$

17 It follows that:

$$
V_{\mu \mu} \frac{\partial \mu}{\partial g_{i}}+V_{\mu v} \frac{\partial v}{\partial g_{i}}=-\alpha_{\mu} V_{\mu} \frac{\partial v}{\partial g_{i}}>0
$$

19 Hence, we get:

$$
\frac{d g_{i}}{d g_{-i}}=\beta \delta \alpha_{\mu} V_{\mu} \frac{\frac{\partial v}{\partial g_{i}}}{\frac{\partial^{2} U}{\partial g_{i}^{2}}} \geq 0
$$

21 and $\frac{d g_{i}}{d g_{-i}}=0$ when $\delta=0$. In other words, under DARA preferences and when $\delta>0$, the land use

22 game between farmers entails strategic complementarities between the land use decisions $g_{i}$ for $i=$ $231 \ldots n$. 


\section{A.3 Comparative statics}

2 In this section, we derive the comparative statics of the equilibrium w.r.t to different parameters. For

3 any parameter $p$, it suffices to differentiate totally the system of first-order conditions:

$$
\frac{\partial U_{i}\left(g_{i}, g_{-i}, p\right)}{\partial g_{i}}=0 \text { for any } i=1 \ldots n
$$

5 and we get:

6

$$
\text { (A1) } \quad \frac{\partial^{2} U_{i}}{\partial g_{i}^{2}} d g_{i}+\sum_{j \neq i} \frac{\partial^{2} U_{i}}{\partial g_{i} \partial g_{j}} d g_{j}+\frac{\partial^{2} U_{i}}{\partial g_{i} \partial p} d p=0 \text { for any } i=1 \ldots n
$$

7 Let us compute first the cross-derivative term $\frac{\partial^{2} U_{i}}{\partial g_{i} \partial p}$. We obtain that:

$$
\begin{aligned}
\frac{\partial^{2} U_{i}}{\partial g_{i} \partial p}=\left(V_{\mu \mu} \frac{\partial \mu}{\partial p}+V_{\mu v} \frac{\partial v}{\partial p}\right) \frac{\partial \mu}{\partial g_{i}}+ & \left(V_{\mu v} \frac{\partial \mu}{\partial p}+V_{v v} \frac{\partial v}{\partial p}\right) \frac{\partial v}{\partial g_{i}} \\
& +V_{\mu} \frac{\partial^{2} \mu}{\partial g_{i} \partial p}+V_{v} \frac{\partial^{2} v}{\partial g_{i} \partial p}
\end{aligned}
$$

9 Rearranging, this can be rewritten as follows:

$$
\begin{aligned}
\frac{\partial^{2} U_{i}}{\partial g_{i} \partial p}=\left(V_{\mu \mu} \frac{\partial \mu}{\partial g_{i}}+V_{\mu v} \frac{\partial v}{\partial g_{i}}\right) \frac{\partial \mu}{\partial p}+ & \left(V_{\mu v} \frac{\partial \mu}{\partial g_{i}}+V_{v v} \frac{\partial v}{\partial g_{i}}\right) \frac{\partial v}{\partial p} \\
& +V_{\mu} \frac{\partial^{2} \mu}{\partial g_{i} \partial p}+V_{v} \frac{\partial^{2} v}{\partial g_{i} \partial p}
\end{aligned}
$$

11 Now, recall that:

$$
\alpha_{\mu}=-\frac{V_{\mu \mu} \alpha+V_{\mu v}}{V_{\mu}}<0(D A R A)
$$

13 and that:

$$
\alpha_{v}=-\frac{V_{\mu v} \alpha+V_{v v}}{V_{\mu}}>0 \text { (Variance vulnerability) }
$$

15 Replacing, we obtain:

$$
\frac{\partial^{2} U_{i}}{\partial g_{i} \partial p}=\left(-\frac{\partial v}{\partial g_{i}} \alpha_{\mu} V_{\mu}\right) \frac{\partial \mu}{\partial p}+\left(-\frac{\partial v}{\partial g_{i}} \alpha_{v} V_{\mu}\right) \frac{\partial v}{\partial p}+V_{\mu} \frac{\partial^{2} \mu}{\partial g_{i} \partial p}+V_{v} \frac{\partial^{2} v}{\partial g_{i} \partial p}
$$

17 To do the comparative statics, let us specialize the model to two farmers as in the experiment $(n=$

18 2). In that case, we get from equation (A1), for $i, j=1,2$ and $j \neq i$ :

$$
\frac{\partial g_{i}}{\partial p}=\frac{1}{\Delta}\left(\frac{\partial^{2} U_{i}}{\partial g_{i} \partial g_{j}} \frac{\partial^{2} U_{j}}{\partial g_{j} \partial p}-\frac{\partial^{2} U_{j}}{\partial g_{j}^{2}} \frac{\partial^{2} U_{i}}{\partial g_{i} \partial p}\right)
$$

Where: 


$$
\Delta=\frac{\partial^{2} U_{j}}{\partial g_{j}^{2}} \frac{\partial^{2} U_{i}}{\partial g_{i}^{2}}-\frac{\partial^{2} U_{i}}{\partial g_{i} \partial g_{j}} \frac{\partial^{2} U_{j}}{\partial g_{i} \partial g_{j}}>0
$$

2 because of the stability of the Nash equilibrium.

4 Impact of change in variances $v_{g}, v_{b}$ and covariance $\sigma_{a \varepsilon}$

5 Consider first a change in variance of the background and foreground risks.

6 Let us start with the foreground risk variance $v_{g}=v_{a}$. Consider equation (A2) for the $v_{a}$ parameter:

7 The variance only appears in the second and last terms since it does not affect the expected wealth $\mu$.

8 We have:

$$
\frac{\partial v}{\partial v_{a}}=g_{i}^{2} \text { and } \frac{\partial^{2} v}{\partial g_{i} \partial v_{a}}=2 g_{i}
$$

10 Consequently,

$$
\frac{\partial^{2} U_{i}}{\partial g_{i} \partial v_{a}}=-\frac{\partial v}{\partial g_{i}} \alpha_{v} V_{\mu} g_{i}^{2}+2 g_{i} V_{v}<0
$$

12 An increase in the foreground risk variance decreases the marginal utility of risk taking $g_{i}$.

13 Now using (A3), we have:

$$
\frac{\partial g_{i}}{\partial v_{a}}=\frac{1}{\Delta}\left(\frac{\partial^{2} U_{i}}{\partial g_{i} \partial g_{j}} \frac{\partial^{2} U_{j}}{\partial g_{j} \partial v_{a}}-\frac{\partial^{2} U_{j}}{\partial g_{j}^{2}} \frac{\partial^{2} U_{i}}{\partial g_{i} \partial v_{a}}\right)<0
$$

15 once again because of strategic complementarities $\left(\frac{\partial^{2} U_{i}}{\partial g_{i} \partial g_{j}}>0\right)$ and concavity $\left(\frac{\partial^{2} U_{j}}{\partial g_{j}^{2}}<0\right)$.

16 Proposition 1. An increase in the variance of the foreground risk decreases the land allocation 17 choice to environment-friendly and risky practices.

18 Let us continue with the background risk variance $v_{b}=v_{\varepsilon}$. Consider equation (A2) for the $v_{\varepsilon}$ 19 parameter.

20 The variance only appears in the second and last terms since it does not affect the expected wealth $\mu$.

21 Moreover, we have

$$
\frac{\partial v}{\partial v_{\varepsilon}}=L_{i}^{2} \text { and } \frac{\partial^{2} v}{\partial g_{i} \partial v_{\varepsilon}}=0 .
$$

23 Consequently, we obtain that

$$
\frac{\partial^{2} U_{i}}{\partial g_{i} \partial v_{\varepsilon}}=-\frac{\partial v}{\partial g_{i}} \alpha_{v} V_{\mu} L_{i}^{2}<0
$$

25 An increase in the background risk variance always decreases the marginal utility of risk taking $g_{i}$.

26 Now using (A3), we have

$$
\frac{\partial g_{i}}{\partial v_{\varepsilon}}=\frac{1}{\Delta}\left(\frac{\partial^{2} U_{i}}{\partial g_{i} \partial g_{j}} \frac{\partial^{2} U_{j}}{\partial g_{j} \partial v_{\varepsilon}}-\frac{\partial^{2} U_{j}}{\partial g_{j}^{2}} \frac{\partial^{2} U_{i}}{\partial g_{i} \partial v_{\varepsilon}}\right)<0
$$


1 because of strategic complementarities $\left(\frac{\partial^{2} U_{i}}{\partial g_{i} \partial g_{j}}>0\right)$ and concavity $\left(\frac{\partial^{2} U_{j}}{\partial g_{j}^{2}}<0\right)$.

2 In the absence of foreground risk $\left(v_{a}=0\right)$, an increase in the variance of the background risk has no 3 impact on $g_{i}$.

4 Proposition 2. An increase in the variance of the background risk decreases the land allocation 5 choice to environment-friendly but only when these practices are risky.

6 Last, we analyze the impact of the correlation between the background and the foreground risk.

7 Consider equation (A2) for the $\sigma_{a \varepsilon}$ parameter. There, the covariance $\sigma_{a \varepsilon}$ only appears in the second 8 and last terms as it does not affect the expected wealth $\mu$. We have:

$$
\frac{\partial v}{\partial \sigma_{a \varepsilon}}=2 L_{i} g_{i} \text { and } \frac{\partial^{2} v}{\partial g_{i} \partial \sigma_{a \varepsilon}}=2 L_{i} \text {. }
$$

10 Consequently:

$$
\frac{\partial^{2} U_{i}}{\partial g_{i} \partial \sigma_{a \varepsilon}}=-2 \frac{\partial v}{\partial g_{i}} \alpha_{v} V_{\mu} L_{i} g_{i}+2 L_{i} V_{v}<0
$$

12 An increase in the covariance decreases the marginal utility of risk taking $g_{i}$, whatever the sign of 13 this correlation.

14 Finally, using (A3), we have:

$$
\frac{\partial g_{i}}{\partial \sigma_{a \varepsilon}}=\frac{1}{\Delta}\left(\frac{\partial^{2} U_{i}}{\partial g_{i} \partial g_{j}} \frac{\partial^{2} U_{j}}{\partial g_{j} \partial \sigma_{a \varepsilon}}-\frac{\partial^{2} U_{j}}{\partial g_{j}^{2}} \frac{\partial^{2} U_{i}}{\partial g_{i} \partial \sigma_{a \varepsilon}}\right)<0
$$

once again because of strategic complementarities $\left(\frac{\partial^{2} U_{i}}{\partial g_{i} \partial g_{j}}>0\right)$ and concavity $\left(\frac{\partial^{2} U_{j}}{\partial g_{j}^{2}}<0\right)$.

17 Proposition 3. A decrease in the covariance between the foreground and the background risks increases the land allocation choice to environment-friendly and risky practices.

\section{The impact of the incentive payment}

21 The parameter $P A Y$ affects positively the expected profit only through the mean of $a$. Consider equation (A2) for the $P A Y$ parameter. From the definition of $\mu$ and $v$, we have:

$$
\frac{\partial \mu}{\partial P A Y}=g_{i} \text { and } \frac{\partial^{2} \mu}{\partial g_{i} \partial P A Y}=1
$$

24 And:

$$
\frac{\partial v}{\partial P A Y}=\frac{\partial^{2} v}{\partial g_{i} \partial P A Y}=0
$$

It follows that:

$$
\frac{\partial^{2} U_{i}}{\partial g_{i} \partial P A Y}=\left(-\frac{\partial v}{\partial g_{i}} \alpha_{\mu} V_{\mu}\right) g_{i}+V_{\mu}>0
$$


1 The payment increases the marginal utility of $g_{i}$.

2 Now using (A3), we have

$$
\frac{\partial g_{i}}{\partial P A Y}=\frac{1}{\Delta}\left(\frac{\partial^{2} U_{i}}{\partial g_{i} \partial g_{j}} \frac{\partial^{2} U_{j}}{\partial g_{j} \partial P A Y}-\frac{\partial^{2} U_{j}}{\partial g_{j}^{2}} \frac{\partial^{2} U_{i}}{\partial g_{i} \partial P A Y}\right)>0
$$

4 because of strategic complementarities $\left(\frac{\partial^{2} U_{i}}{\partial g_{i} \partial g_{j}}>0\right)$ and concavity $\left(\frac{\partial^{2} U_{j}}{\partial g_{j}^{2}}<0\right)$.

5 Proposition 4. An increase in $P A Y$ induces each farmer to raise its land use allocation of 6 environment-friendly practices. ${ }^{15}$

\section{The impact of strategic complementarities}

9 The impact of the parameter $\delta$ that scales the importance of strategic complementarities can also be 10 evaluated using the above analysis. We have the following result.

11 Proposition 5. An increase in $\delta$, that is the relative importance of others' actions in individual 12 payoff, leads each farmer to raise its own land use allocation to environment-friendly practices.

13 From equation (A3), we obtain:

$$
\frac{\partial g_{i}}{\partial \delta}=\frac{1}{\Delta}\left(\frac{\partial^{2} U_{i}}{\partial g_{i} \partial g_{j}} \frac{\partial^{2} U_{j}}{\partial g_{j} \partial \delta}-\frac{\partial^{2} U_{j}}{\partial g_{j}^{2}} \frac{\partial^{2} U_{i}}{\partial g_{i} \partial \delta}\right)
$$

15 and from equation (A2),

$$
\frac{\partial^{2} U_{i}}{\partial g_{i} \partial \delta}=\left(-\frac{\partial v}{\partial g_{i}} \alpha_{\mu} V_{\mu}\right) \beta g_{-i}>0
$$

$$
\text { As } \frac{\partial \mathrm{v}}{\partial \delta}=\frac{\partial^{2} \mu}{\partial \mathrm{g}_{\mathrm{i}} \partial \delta}=\frac{\partial^{2} \mathrm{v}}{\partial \mathrm{g}_{\mathrm{i}} \partial \delta}=0
$$

19 Similarly, $\frac{\partial^{2} U_{j}}{\partial g_{j} \partial \delta}=\left(-\frac{\partial v}{\partial g_{j}} \alpha_{\mu} V_{\mu}\right) \beta g_{-j}>0$. It follows that $\frac{\partial g_{i}}{\partial \delta}>0$ because of strategic

20 complementarity $\left(\frac{\partial^{2} U_{i}}{\partial g_{i} \partial g_{j}}>0\right)$ and concavity $\left(\frac{\partial^{2} U_{j}}{\partial g_{j}^{2}}<0\right)$.

21 Hence, the bigger the strategic complementarities (and thus strategic uncertainty) the stronger the

22 incentives to adopt environment-friendly practices.

${ }^{15}$ A similar result can be expected with respect to an increase in $\beta$, the marginal utility of $g$. 


\section{Appendix B: results of non-parametric tests}

2 We relied on the Wilcoxon rank-sum two-sample test to compare the choices of participants in the

3 four risk settings (between-subject treatments). Results are presented in Table A.

Table A: Results of Wilcoxon two samples tests, with no payment

\begin{tabular}{|c|c|c|c|}
\cline { 2 - 4 } \multicolumn{1}{c|}{} & ForeOnly & BackOnly & Fore\&Back \\
\hline Benchmark & $\begin{array}{c}\mathrm{z}=3.268 \\
\operatorname{Prob}>|\mathrm{z}|=0.0011 * * *\end{array}$ & $\begin{array}{c}\mathrm{z}=3.742 \\
\operatorname{Prob}>|\mathrm{z}|=0.0002 * * *\end{array}$ & $\begin{array}{c}\mathrm{z}=4.553 \\
\operatorname{Prob}>|\mathrm{z}|=0.0000 * * *\end{array}$ \\
\hline ForeOnly & & $\begin{array}{c}\mathrm{z}=-0.183 \\
\operatorname{Prob}>|\mathrm{z}|=0.8551-\end{array}$ & $\begin{array}{c}\mathrm{z}=1.813 \\
\operatorname{Prob}>|\mathrm{z}|=0.0698^{*}\end{array}$ \\
\hline BackOnly & & & $\begin{array}{c}\mathrm{z}=2.140 \\
\text { Prob }>|\mathrm{z}|=0.0324 * *\end{array}$ \\
\hline
\end{tabular}

The number of stars indicates the significance level : *** is significant at $1 \%$, ** is significant at $5 \%$, is significant at $10 \%$, - is not significant.

Kruskal-Wallis equality-of-populations rank test (chi-squared $=41.771$, prob $=0.0001)$ : we can reject the hypothesis the four samples are from the same population.

5 In order to analyze the impact of the incentive payment and the way it might influence it differently depending on the risk contexts, we rely on a Wilcoxon matched pair test to compare the choices of participants without and with incentive payment. Results are presented in Table B.

Table B : Average number of hectares farmed with environment-friendly practices and results of

Wilcoxon matched pair tests

\begin{tabular}{|c|c|c|c|c|}
\hline & Benchmark & ForeOnly & BackOnly & Fore\&Back \\
\hline $\begin{array}{c}\text { No payment } \\
\text { scenario }\end{array}$ & 63 & 50 & 50 & 41 \\
\hline Payment scenario & 73 & 61 & 60 & 41 \\
\hline difference & $\begin{array}{c}\mathrm{z}=-4.461 \\
\operatorname{Prob}>|\mathrm{z}|=0.0000 \\
* * *\end{array}$ & $\begin{array}{c}\mathrm{z}=-3.691 \\
\text { Prob }>|\mathrm{z}|=0.0002 \\
* * *\end{array}$ & $\begin{array}{c}\mathrm{z}=-3.488 \\
\text { Prob }>|\mathrm{z}|=0.0005 \\
* * *\end{array}$ & $\begin{array}{c}\mathrm{z}=-0.570 \\
\text { Prob }>|\mathrm{z}|=0.5686 \\
-\end{array}$ \\
\hline
\end{tabular}




\section{Appendix C: instructions (translated from French)}

\section{Economic study on agricultural practices}

\section{Introduction}

4 Thank you for participating in this survey, which is part of a research project in economics and 5 psychology at the University of Angers. This research is entirely funded by the University of Angers, 6 and it is entirely independent of any political interest or the agricultural profession.

7 Our aim is to increase understanding of farmers' motivations in various scenarios.

8 The survey is divided into five parts and takes about 30 minutes to complete.

9 Each part (from Part 1 to Part 4) consists of:

10 - explanations

11 - a comprehension test to check that you have fully understood the explanations

12 - decisions to be taken. There is no right or wrong answer. We are just seeking to know more about 13 your decision making.

Why should you participate in this survey?

16 Scientific research

First, your answers will be useful to scientific research regarding agricultural policies. It is essential that studies that are independent of States, European institutions, and agricultural trade unions be conducted on this topic.

\section{Remuneration}

Second, as a token of our gratitude, you will receive within a couple of weeks a gift card valid in numerous brands. You can view the list of these brands on the «illicado » site.

The exact amount of the gift card will depend upon your survey answers. You will earn points in each part of the survey, and these points will be converted into euros credited to the gift card, based on the following rate: 200 points $=1$ euro.

The gift card amount will be between 1,000 and 6,000 points (hence, between 5 and 30 euros).

\section{Privileged access to the results}

Finally, a synthesis of the findings will be emailed to you.

What will the survey data be used for?

The data collected in the survey will be used for scientific purposes only. No data will be given to the State or any other body external to the University. The survey results will be used for one or several scientific publications that will be made available to the general public on the Internet.

The data will be anonymous: your name and address will be used only to send you the gift card; then, they will be erased from our database.

Should you have any questions, please feel free to email us. You will receive an answer within 24 hours, and you will then be able to return to the survey.

39 The final deadline for your participation in the survey is May 10, 2017. After this date, the survey

40 will no longer be available. 
Part 1

In Part 1, you have one decision only to take.

You have 500 points. You may decide to keep these points or to invest them all or some of them.

The investment we offer you is risky: there is a 50/50 chance that the project fails and a 50/50 chance that it succeeds. The computer will run a random draw to decide whether the project is successful or not.

Should the computer draw "success", the points invested are multiplied by 2.5 . Hence, you win the points non invested plus 2.5 times the points invested.

Should the computer draw "fail", all the points invested are lost. Hence, your investment is deducted from your original number of points (i.e. 500 points).

First example:

If you decide to invest 400 out of the 500 points.

If the computer draws "success", you win $500-400+2.5 \times 400=1,100$ points

If the computer draws "fail", you lose the points invested, and you are left with 100 points.

Second example:

If you decide to invest 100 out of the 500 points.

If the computer draws "success", you win $500-100+2.5$ x 100=650 points

If the computer draws "fail", you lose the points invested, and you are left with 400 points.

Remember: The points you win in Part 1 will be added to your total of points, then will be converted into euros credited to the gift card, based on the following rate: 200 points $=1$ euro.

Comprehension test:

Please answer the following quiz to check you have understood the instructions.

How much are 500 points worth?

Please select one answer only:

$€ 0.50$

$€ 2.50$

$€ 5$

If you decide to invest 250 points, how many points will you receive?

If the project fails, I will receive:

Please select one answer only:

0 point

250 points

875 points

If the project succeeds, I will receive:

Please select one answer only:

0 point

250 points

875 points 
Test answers:

500 points are worth $€ 2.50$.

3 If you invest 250 points and the project fails, you will receive 0 point.

4 If the project succeeds, you will receive 875 points.

5

\section{Decision}

You are now able to make a decision for Part 1.

You can click on "Previous" to read the explanations again.

Remember: 200 points $=€ 1$

How much do you wish to invest?

12 The total must be 500 points.

13 How many points do you wish to invest?

14 How many points do you wish to keep?

How many points do you think the other survey participants will invest on average?

Your answer must be 1,000 at the most.

18 Enter an integer only in this field.

\section{Part 2}

In Part 2, you are partnered with another person whom you do not know. This person is randomly selected by the computer from among all the participants to the survey. At no time will you know who the person is, and the person will not know who you are either.

You need to select the number of points you keep for yourself and the number of points you give to this other person. This person will do the same.

Hence, you will receive the points you decided to keep for yourself and the points this other person decided to give you.

Remember: The points you win in Part 2 will be added to your total of points, then will be converted into euros credited to the gift card, based on the following rate: 200 points $=1$ euro.

\section{Comprehension test:}

Please answer the following quiz to check you have understood the instructions.

If you decide as indicated in the first table and the other person decides as indicated in the second table, how many points are you going to receive?

Your decision:

\begin{tabular}{|l|l|l|l|l|l|l|l|l|l|}
\hline You keep for yourself & 300 & 350 & 400 & 450 & 500 & 550 & 600 & 650 & 700 \\
\hline You give the other person & 800 & 700 & 600 & 500 & 400 & 300 & 200 & 100 & 0 \\
\hline & & & & & $X$ & & & & \\
\hline
\end{tabular}

40

41 The other person's decision:

\begin{tabular}{|ll|l|l|l|l|l|l|l|l|l|}
\hline $\begin{array}{l}\text { He/she keeps for } \\
\text { himself/herself: }\end{array}$ & 300 & 350 & 400 & 450 & 500 & 550 & 600 & 650 & 700 \\
\hline He/she gives me & 800 & 700 & 600 & 500 & 400 & 300 & 200 & 100 & 0 \\
\hline
\end{tabular}


Please select one answer only:

I will receive 500 points

I will receive 700 points

I will receive 900 points

Answer:

In this case, you will receive 700 points. 500 points you keep for yourself +200 points the other person decided to give you.

\section{Decision}

You are now able to make a decision for Part 2.

You can click on "Previous" to read the explanations again

Remember: 200 points $=€ 1$

For each table, which distribution of points do you decide?

Remember that you need to decide on various distributions of points between you and another person. You receive the points you decided to keep for yourself plus the points another person has given you.

The computer draws a number between 1 and 6 . This number corresponds to the decision used to calculate your points in Part 2.

Decision 1

\begin{tabular}{|l|l|l|l|l|l|l|l|l|l|}
\hline You receive & 425 & 425 & 425 & 425 & 425 & 425 & 425 & 425 & 425 \\
\hline The other person receives & 425 & 390 & 340 & 295 & 250 & 205 & 165 & 120 & 90 \\
\hline
\end{tabular}

26

27

28

29

Decision 2

\begin{tabular}{|l|l|l|l|l|l|l|l|l|l|}
\hline You receive & 425 & 435 & 445 & 455 & 465 & 470 & 480 & 490 & 500 \\
\hline The other person receives & 75 & 80 & 120 & 140 & 165 & 185 & 205 & 230 & 250 \\
\hline
\end{tabular}

Which distribution do you decide upon? (for yourself; for the other person)

Please select one answer only

Which distribution do you decide upon? (for yourself; for the other person)

Please select one answer only

Decision 3

\begin{tabular}{|l|l|l|l|l|l|l|l|l|l|}
\hline You receive: & 250 & 270 & 295 & 315 & 340 & 360 & 380 & 405 & 425 \\
\hline The other person receives & 500 & 490 & 480 & 470 & 465 & 455 & 445 & 435 & 425 \\
\hline
\end{tabular}

Which distribution do you decide upon? (for yourself; for the other person)

Please select one answer only

Decision 4 


\begin{tabular}{|l|l|l|l|l|l|l|l|l|l|}
\hline You receive & 250 & 270 & 295 & 315 & 340 & 360 & 380 & 405 & 425 \\
\hline The other person receives & 500 & 445 & 395 & 340 & 290 & 235 & 180 & 130 & 75 \\
\hline
\end{tabular}

Decision 6

\begin{tabular}{|l|l|l|l|l|l|l|l|l|l|}
\hline You receive & 500 & 490 & 480 & 470 & 465 & 455 & 445 & 435 & 425 \\
\hline The other person receives & 250 & 270 & 295 & 315 & 340 & 360 & 380 & 405 & 425 \\
\hline
\end{tabular}

\section{Part 3}

13 This survey part may appear to be rather complicated. Hence, take your time before responding 14 because your gain will depend upon your decision. Remember: The points you win in Part 3 will be 15 added to your total of points, then will be converted into euros credited to the gift card, based on the 16 following rate: 200 points $=1$ euro.

17 You play the role of a farmer who has 80 hectares cultivated in large-scale crops.

18 The computer will draw another participant in this survey to be your "neighbor". At no time will you

19 know who the person is, and the person will not know who you are either.

20 There are two possible crop systems: the orange one and the purple one. The purple system is more 21 effective than the orange one to reduce the environmental impact of agricultural production.

22 You need to select which crop system you wish to use per tract of 20 hectares.

\section{Treatment 1}

24 Your gain (in points) for Part 3 is determined as follows:

25 Revenue:

26 Your crops bring you a revenue of 15 points per hectare, regardless of the crop system put in place.

27 The revenue per hectare remains the same.

28 Observations carried out in the farms that have implemented the purple crop system show that the 29 revenue is the same as that of the orange system.

30 Production costs: 
1 The production costs with the orange system are 4 points per hectare.

2 The production costs with the purple system are 7 points per hectare. These costs are higher than

3 those of the orange system because implementation requires more equipment or more work.

4 Ecosystem services:

$5 \quad$ Setting up the purple system contributes to the ecosystem services nature provides.

6 The total number of hectares cultivated with the purple system by you and your neighbor determines

7 the quality of these services provided by nature.

8 In other words, the purple system generates additional revenue when it is adopted collectively.

9 The total number of hectares cultivated with the purple system by you and your neighbor will bring 10 you an additional gain (in points) that is equal to twice the cultivated surface. For instance, if both 11 farmers use the purple system to cultivate half their surface, the additional gain is $2 \times(40+40)=160$ 12 points.

Comprehension test:

Please answer the following quiz to check you have understood the instructions.

My number of points in Part 3 is determined by the crop system I decide to put in place (orange or purple).

19 Please select one answer only:

20 True

21 False

The purple system is less expensive for me if my neighbor also implements it.

Please select one answer only:

True

False

I will receive a revenue of 15 points per hectare regardless of the number of hectares I cultivate with the purple system.

Please select one answer only:

True

False

The sum of the number of hectares cultivated with the orange crop system and of the number of hectares cultivated with the purple crop system determines the additional gain related to the ecosystem services.

Please select one answer only:

True

$39 \quad$ False

Test answers:

The number of points you obtain in Part 3 is determined by the crop system you decide to set up (orange or purple). 
1 The purple system is not less expensive for you if your neighbor also puts it in place. The cost of the 2 purple system is the same, but you benefit from an additional gain related to the ecosystem services 3 if your neighbor also puts it in place.

4 You will receive a revenue of 15 points per hectare regardless of the number of hectares you 5 cultivate with the purple system.

The sum of the number of hectares cultivated with the orange crop system and of the number of hectares cultivated with the purple crop system does not determine the additional gain related to the ecosystem services. What determines the additional gain related to the ecosystem services is the sum of the number of hectares cultivated with the purple crop system by you and your neighbor.

\section{Decision}

You are now able to make a decision for Part 3.

You can click on "Previous" to read the explanations again

Remember: 200 points $=€ 1$

You have no calculations to make. These tables indicate your gain depending upon your decision and the total number of hectares cultivated with the purple system. To obtain your total gain, you need to add your individual gain and the additional gain related to the ecosystem services.

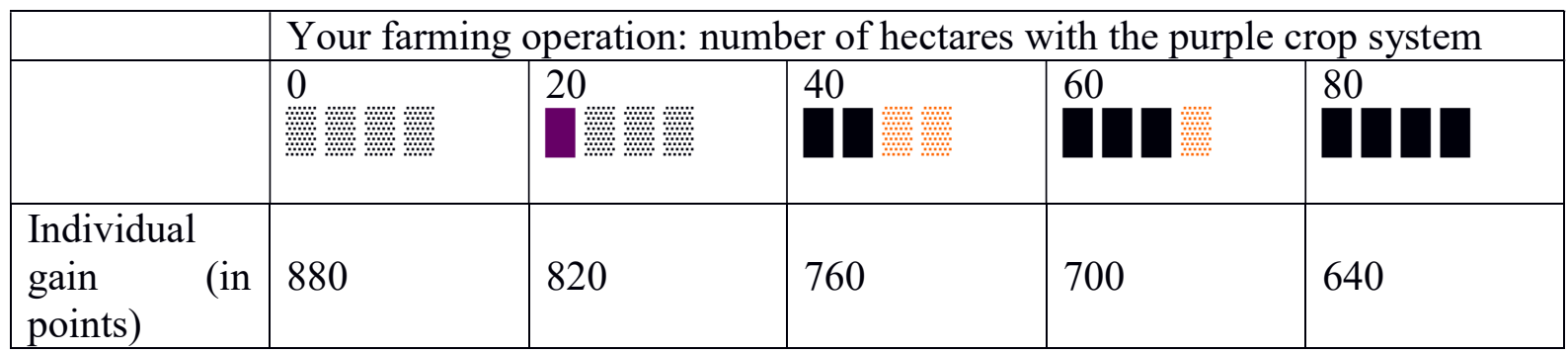

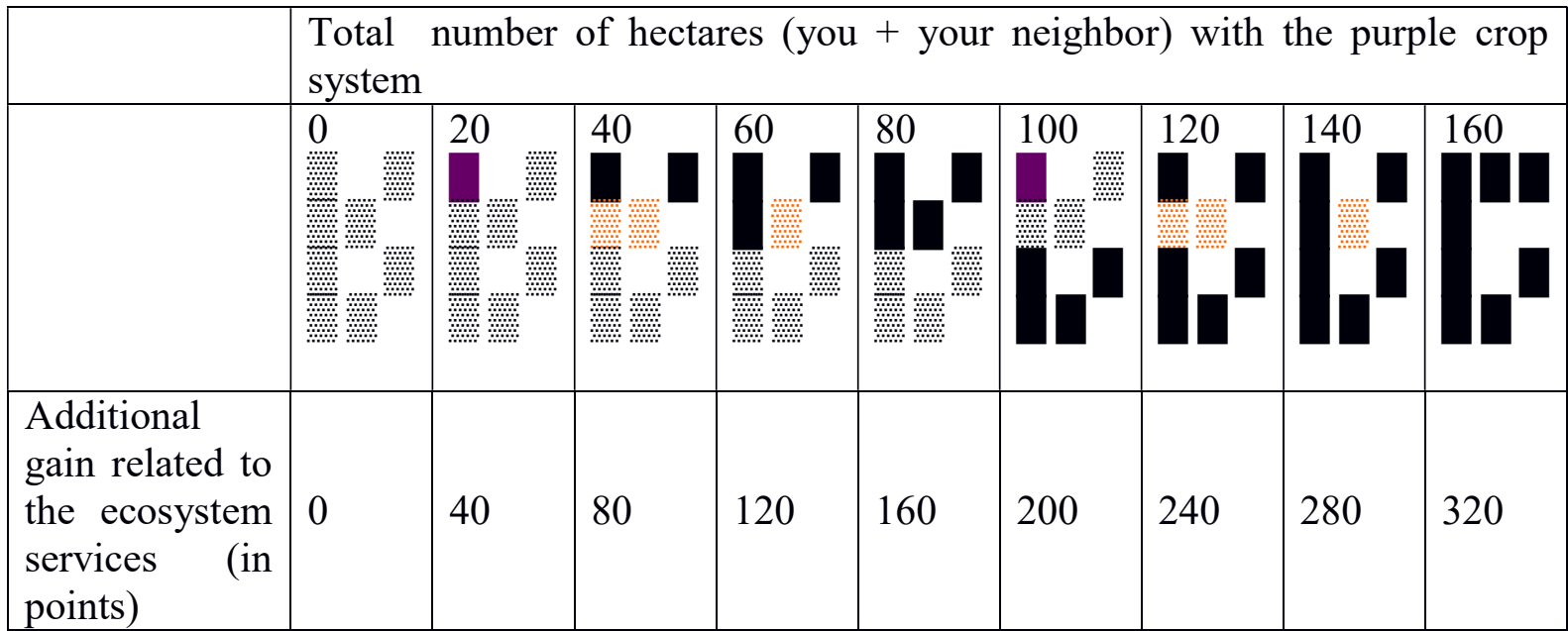

Your decision (orange system hectares; purple system hectares)

\begin{tabular}{|l|l|l|l|l|l|}
\hline Hectares with the orange crop system & 0 & 20 & 40 & 60 & 80 \\
\hline Hectares with the purple crop system & 80 & 60 & 40 & 20 & 0 \\
\hline
\end{tabular}

27 Please select one answer only 
What do you believe will be your neighbor's decision? (orange system hectares; purple system hectares)

\begin{tabular}{|l|l|l|l|l|l|}
\hline Hectares with the orange crop system & 0 & 20 & 40 & 60 & 80 \\
\hline Hectares with the purple crop system & 80 & 60 & 40 & 20 & 0 \\
\hline
\end{tabular}

\section{Please select one answer only}

\section{Treatment 2}

Your gain (in points) for Part 3 is determined as follows:

\section{Revenue:}

Your crops bring you a revenue of 15 points per hectare, regardless of the crop system put in place. Observations carried out in the farms that have implemented the purple crop system show that the revenue is the same as that of the orange system.

\section{Production costs:}

The orange system production cost is fixed, known, and equal to 4 points per hectare. In contrast, the purple system production cost is not known in advance. It may increase through adverse events such as unpredictable weather conditions or the onset of diseases.

The computer will randomly determine whether there is an adverse event (a 50/50 chance). The production cost will thus depend upon this random draw. If an adverse event occurs, the cost of the purple system is 9 points per hectare. If no adverse event occurs, the cost of the purple system is 5 points per hectare.

\section{Ecosystem services:}

Setting up the purple system contributes to the ecosystem services nature provides.

The total number of hectares cultivated with the purple system by you and your neighbor determines the quality of these services provided by nature.

In other words, the purple system generates additional revenue when it is adopted collectively.

The total number of hectares cultivated with the purple system by you and your neighbor will bring you an additional gain (in points) that is equal to twice the cultivated surface. For instance, if both farmers use the purple system to cultivate half their surface, the additional gain is $2 \times(40+40)=160$ points.

\section{Comprehension test:}

Please answer the following quiz to check you have understood the instructions.

My number of points in Part 3 is determined by the crop system I decide to put in place (orange or purple).

Please select one answer only:

True

False

The purple system is less expensive for me if my neighbor also implements it. Please select one answer only:

True 
False

2 I will receive a revenue of 15 points per hectare regardless of the number of hectares I cultivate with

3 the purple system.

4 Please select one answer only:

5 True

$6 \quad$ False

The sum of the number of hectares cultivated with the orange crop system and of the number of hectares cultivated with the purple crop system determines the additional gain related to the ecosystem services.

Please select one answer only:

True

False

Test answers:

The number of points you obtain in Part 3 is determined by the crop system you decide to set up (orange or purple).

The purple system is not less expensive for you if your neighbor also puts it in place. The cost of the purple system is the same, but you benefit from an additional gain related to the ecosystem services if your neighbor also puts it in place.

You will receive a revenue of 15 points per hectare regardless of the number of hectares you cultivate with the purple system.

The sum of the number of hectares cultivated with the orange crop system and of the number of hectares cultivated with the purple crop system does not determine the additional gain related to the ecosystem services. What determines the additional gain related to the ecosystem services is the sum of the number of hectares cultivated with the purple crop system by you and your neighbor.

\section{Decision}

You are now able to make a decision for Part 3.

You can click on "Previous" to read the explanations again

Remember: 200 points $=€ 1$

You have no calculations to make. These tables indicate your gain depending upon your decision and the total number of hectares cultivated with the purple system. To obtain your total gain, you need to add your individual gain and the additional gain related to the ecosystem services.

\begin{tabular}{|c|c|c|c|c|c|c|}
\hline & & \multicolumn{5}{|c|}{$\begin{array}{l}\text { Your farming operation: number of hectares with } \\
\text { the purple crop system }\end{array}$} \\
\hline & & 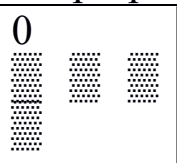 & 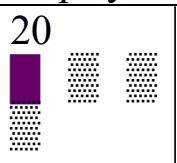 & $\begin{array}{l}40 \\
\end{array}$ & & ${ }^{80}$ \\
\hline $\begin{array}{l}\text { Individual gain (in } \\
\text { points) }\end{array}$ & $\begin{array}{l}\text { No adverse event } \\
\text { Cost of the purple } \\
\text { system: } 5 \text { pts/ha }\end{array}$ & 880 & 860 & 840 & 820 & 800 \\
\hline
\end{tabular}




\begin{tabular}{|l|l|l|l|l|l|l|}
\hline & $\begin{array}{l}\text { Adverse event: } \\
\text { Cost of the purple } \\
\text { system: } 9 \text { pts/ha }\end{array}$ & 880 & 780 & 680 & 580 & 480 \\
\hline
\end{tabular}

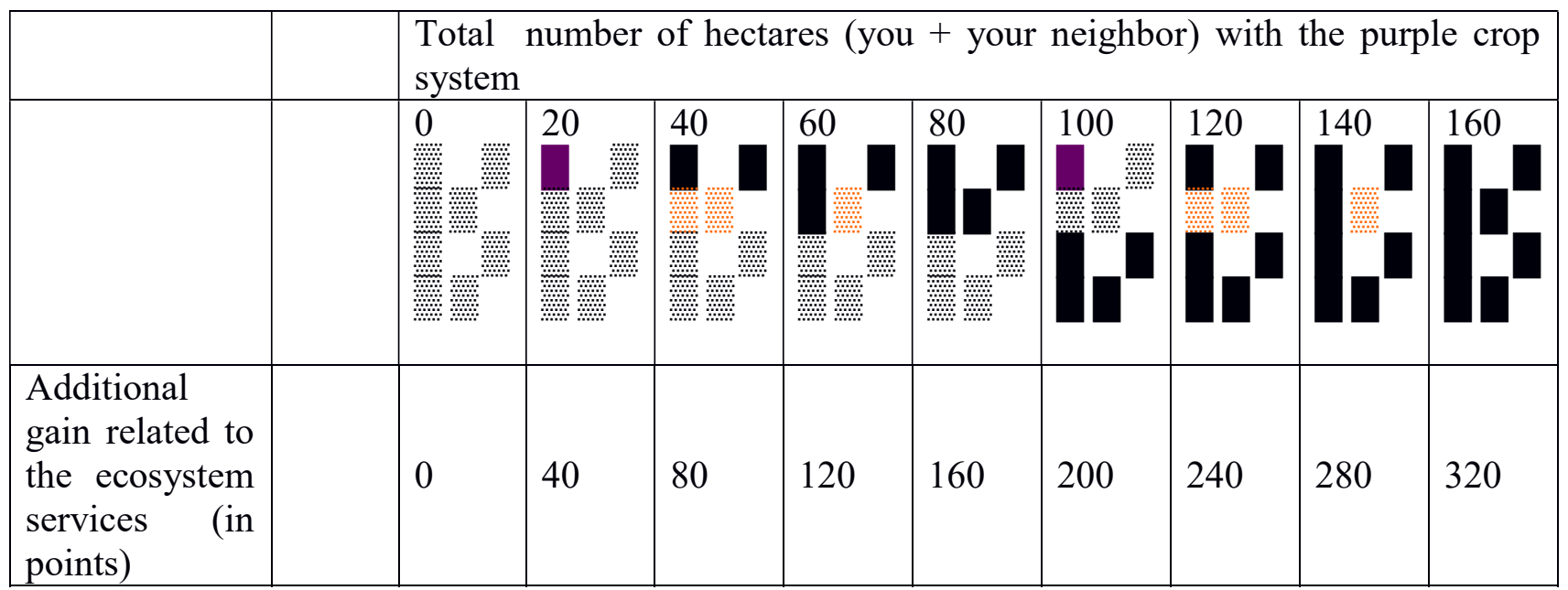

2

3 Your decision (orange system hectares; purple system hectares)

\begin{tabular}{|l|l|l|l|l|l|}
\hline Hectares with the orange crop system & 0 & 20 & 40 & 60 & 80 \\
\hline Hectares with the purple crop system & 80 & 60 & 40 & 20 & 0 \\
\hline
\end{tabular}

\section{Please select one answer only}

What do you believe will be your neighbor's decision? (orange system hectares; purple system hectares)

\begin{tabular}{|l|l|l|l|l|l|}
\hline Hectares with the orange crop system & 0 & 20 & 40 & 60 & 80 \\
\hline Hectares with the purple crop system & 80 & 60 & 40 & 20 & 0 \\
\hline
\end{tabular}

Please select one answer only

\section{Treatment 3}

Your gain (in points) for Part 3 is determined as follows:

\section{Revenue:}

Your crops bring you the same revenue per hectare, regardless of the crop system put in place. Observations carried out in the farms that have implemented the purple crop system show that the revenue is the same as that of the orange system.

However, the revenue is not known in advance because it can decrease through adverse events that reduce yield and/or prices on the agricultural markets.

The computer will randomly determine whether there is an adverse event (a 50/50 chance). The revenue per hectare will thus depend upon this draw. If an adverse event occurs, the revenue per hectare is 10 points per hectare. If no adverse event occurs, the revenue per hectare is 20 points per hectare.

\section{Production costs:}

The production costs with the orange system are 4 points per hectare.

The production costs with the purple system are 7 points per hectare. These costs are higher than those of the orange system because implementation requires more equipment or more work. 
Ecosystem services:

2 Setting up the purple system contributes to the ecosystem services nature provides.

3 The total number of hectares cultivated with the purple system by you and your neighbor determines

4 the quality of these services provided by nature.

5 In other words, the purple system generates additional revenue when it is adopted collectively.

6 The total number of hectares cultivated with the purple system by you and your neighbor will bring

7 you an additional gain (in points) that is equal to twice the cultivated surface. For instance, if both

8 farmers use the purple system to cultivate half their surface, the additional gain is $2 \times(40+40)=160$

9 points.

11 Comprehension test:

Please answer the following quiz to check you have understood the instructions.

My number of points in Part 3 is determined by the crop system I decide to put in place (orange or purple).

Please select one answer only:

True

False

The purple system is less expensive for me if my neighbor also implements it. Please select one answer only:

True

False

My revenue depends only upon the number of hectares cultivated with the purple system.

Please select one answer only:

True

False

The sum of the number of hectares cultivated with the orange crop system and of the number of hectares cultivated with the purple crop system determines the additional gain related to the ecosystem services.

Please select one answer only:

True

False

\section{Test answers:}

The number of points you obtain in Part 3 is determined by the crop system you decide to set up (orange or purple).

The purple system is not less expensive for you if your neighbor also puts it in place. The cost of the purple system is the same, but you benefit from an additional gain related to the ecosystem services if your neighbor also puts it in place.

Your revenue does not depend only upon the number of hectares cultivated with the purple system since it can decrease through adverse events that reduce yield and/or prices on the agricultural markets. 
The sum of the number of hectares cultivated with the orange crop system and of the number of hectares cultivated with the purple crop system does not determine the additional gain related to the ecosystem services. What determines the additional gain related to the ecosystem services is the sum of the number of hectares cultivated with the purple crop system by you and your neighbor.

\section{Decision}

You are now able to make a decision for Part 3.

You can click on "Previous" to read the explanations again

9 Remember: 200 points $=€ 1$

You have no calculations to make. These tables indicate your gain depending upon your decision and the total number of hectares cultivated with the purple system. To obtain your total gain, you need to

\begin{tabular}{|c|c|c|c|c|c|c|}
\hline & & \multicolumn{5}{|c|}{$\begin{array}{l}\text { Your farming operation: number of hectares with the } \\
\text { purple crop system }\end{array}$} \\
\hline & & 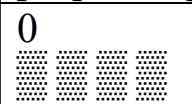 & 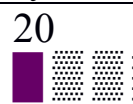 & 40 & 60 & 80 \\
\hline \multirow[t]{2}{*}{$\begin{array}{l}\text { Individual gain (in } \\
\text { points) }\end{array}$} & $\begin{array}{l}\text { No adverse } \\
\text { event } \\
\text { Revenue: } 20 \\
\text { pts/ha }\end{array}$ & 1280 & 1220 & 1160 & 1100 & 1040 \\
\hline & $\begin{array}{l}\text { Adverse event: } \\
\text { Revenue: } 10 \\
\text { pts/ha }\end{array}$ & 480 & 420 & 360 & 300 & 240 \\
\hline
\end{tabular}

16

17

19 Your decision (orange system hectares; purple system hectares)

\begin{tabular}{|l|l|l|l|l|l|}
\hline Hectares with the orange crop system & 0 & 20 & 40 & 60 & 80 \\
\hline Hectares with the purple crop system & 80 & 60 & 40 & 20 & 0 \\
\hline
\end{tabular}

Please select one answer only

\begin{tabular}{|l|l|l|l|l|l|l|l|l|l|}
\hline & \multicolumn{6}{|l|}{$\begin{array}{l}\text { Total number of hectares (you + your neighbor) with the purple crop } \\
\text { system }\end{array}$} \\
\hline & $\begin{array}{l}0 \\
\text { Additional } \\
\text { gain related to } \\
\text { the ecosystem } \\
\text { services (in } \\
\text { points). }\end{array}$ & 40 & 80 & 120 & 160 & 200 & 240 & 280 & 320 \\
\hline
\end{tabular}


1 What do you believe will be your neighbor's decision? (orange system hectares; purple system 2 hectares)

\begin{tabular}{|l|l|l|l|l|l|}
\hline Hectares with the orange crop system & 0 & 20 & 40 & 60 & 80 \\
\hline Hectares with the purple crop system & 80 & 60 & 40 & 20 & 0 \\
\hline
\end{tabular}

3 Please select one answer only

4 
Treatment 4

Your gain (in points) for Part 3 is determined as follows:

Revenue:

Your crops bring you the same revenue per hectare, regardless of the crop system put in place. Observations carried out in the farms that have implemented the purple crop system show that the revenue is the same as that of the orange system.

However, the revenue is not known in advance because it can decrease through adverse events that reduce yield and/or prices on the agricultural markets.

The computer will randomly determine whether there is an adverse event (a 50/50 chance). The revenue per hectare will thus depend upon this draw. If an adverse event occurs, the revenue per hectare is 10 points per hectare. If no adverse event occurs, the revenue per hectare is 20 points per hectare.

\section{Production costs:}

The orange system production cost is fixed, known, and equal to 4 points per hectare.

In contrast, the purple system production cost is not known in advance. It may increase through adverse events such as unpredictable weather conditions or the onset of diseases.

The computer will randomly determine whether there is an adverse event that affects the production costs with the purple system occurs or not (a 50/50 chance). The production cost will thus depend upon this random draw. If an adverse event occurs, the cost of the purple system is 9 points per hectare. If no adverse event occurs, the cost of the purple system is 5 points per hectare.

\section{Ecosystem services:}

Setting up the purple system contributes to the ecosystem services nature provides.

The total number of hectares cultivated with the purple system by you and your neighbor determines the quality of these services provided by nature.

In other words, the purple system generates additional revenue when it is adopted collectively.

The total number of hectares cultivated with the purple system by you and your neighbor will bring you an additional gain (in points) that is equal to twice the cultivated surface. For instance, if both farmers use the purple system to cultivate half their surface, the additional gain is $2 \times(40+40)=160$ points.

Comprehension test:

Please answer the following quiz to check you have understood the instructions.

My number of points in Part 3 is determined by the crop system I decide to put in place (orange or purple).

Please select one answer only:

True

False

The purple system is less expensive for me if my neighbor also implements it.

Please select one answer only:

True

False

My revenue depends only upon the number of hectares cultivated with the purple system.

Please select one answer only: 
The sum of the number of hectares cultivated with the orange crop system and of the number of hectares cultivated with the purple crop system determines the additional gain related to the ecosystem services.

Please select one answer only:

True / False

Test answers:

The number of points you obtain in Part 3 is determined by the crop system you decide to set up (orange or purple).

The purple system is not less expensive for you if your neighbor also puts it in place. The cost of the purple system is the same, but you benefit from an additional gain related to the ecosystem services if your neighbor also puts it in place.

Your revenue does not depend only upon the number of hectares cultivated with the purple system since it can decrease through adverse events that reduce yield and/or prices on the agricultural markets.

The sum of the number of hectares cultivated with the orange crop system and of the number of hectares cultivated with the purple crop system does not determine the additional gain related to the ecosystem services. What determines the additional gain related to the ecosystem services is the sum of the number of hectares cultivated with the purple crop system by you and your neighbor.

\section{Decision}

You are now able to make a decision for Part 3.

You can click on "Previous" to read the explanations again

Remember: 200 points $=€ 1$

You have no calculations to make. These tables indicate your gain depending upon your decision and the total number of hectares cultivated with the purple system. To obtain your total gain, you need to add your individual gain and the additional gain related to the ecosystem services.

\begin{tabular}{|c|c|c|c|c|c|c|}
\hline & & \multicolumn{5}{|c|}{$\begin{array}{l}\text { Your farming operation: number of } \\
\text { hectares with the purple crop system }\end{array}$} \\
\hline & & 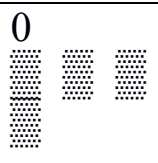 & 200 & 40 & 60 & \\
\hline \multirow[t]{4}{*}{$\begin{array}{l}\text { Individual } \\
\text { gain (in } \\
\text { points) }\end{array}$} & $\begin{array}{l}\text { No adverse event: } \\
\text { High revenue: } 20 \mathrm{pts} / \mathrm{ha} \\
\text { Low cost of the purple system: } 5 \mathrm{pts} / \mathrm{ha}\end{array}$ & 1280 & 1260 & 1240 & 1220 & 1200 \\
\hline & $\begin{array}{l}\text { An adverse event: } \\
\text { High revenue: } 20 \mathrm{pts} / \mathrm{ha} \\
\text { High cost of the purple system: } 9 \mathrm{pts} / \mathrm{ha}\end{array}$ & 1280 & 1180 & 1080 & 980 & 880 \\
\hline & $\begin{array}{l}\text { An adverse event: } \\
\text { Low revenue: } 10 \mathrm{pts} / \mathrm{ha} \\
\text { Low cost of the purple system: } 5 \mathrm{pts} / \mathrm{ha}\end{array}$ & 480 & 460 & 440 & 420 & 400 \\
\hline & Two adverse events & 480 & 380 & 280 & 180 & 80 \\
\hline
\end{tabular}




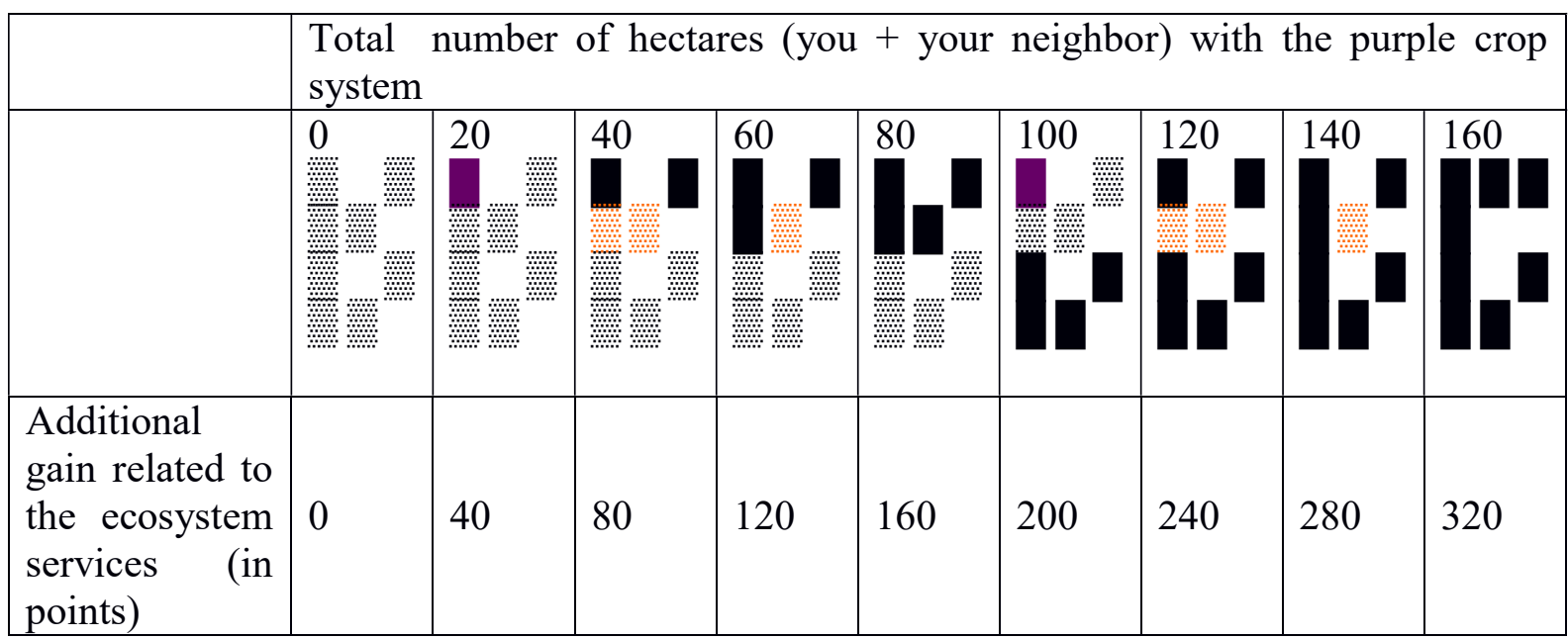

3 Your decision (orange system hectares; purple system hectares)

\begin{tabular}{|l|l|l|l|l|l|}
\hline Hectares with the orange crop system & 0 & 20 & 40 & 60 & 80 \\
\hline Hectares with the purple crop system & 80 & 60 & 40 & 20 & 0 \\
\hline
\end{tabular}

Please select one answer only

What do you believe will be your neighbor's decision? (orange system hectares; purple system hectares)

\begin{tabular}{|l|l|l|l|l|l|}
\hline Hectares with the orange crop system & 0 & 20 & 40 & 60 & 80 \\
\hline Hectares with the purple crop system & 80 & 60 & 40 & 20 & 0 \\
\hline
\end{tabular}

Please select one answer only

95 Part 4

\section{Treatment 1}

11 This part is similar to the previous one. The only difference is that a subsidy has been set up for those 12 farmers who undertake to set up the purple crop system,

13 Remember: The points you win in Part 4 will be added to your total of points, then will be converted 14 into euros credited to the gift card, based on the following rate: 200 points $=1$ euro.

Your gain (in points) for Part 4 is determined as follows:

Revenue, production costs, and the gain related to the ecosystem services are identical to the preceding part.

\section{Revenue:}

Your crops bring you a revenue of 15 points per hectare, regardless of the crop system put in place. Observations carried out in the farms that have implemented the purple crop system show that the revenue is the same as that of the orange system.

Production costs:

The production costs with the orange system are 4 points per hectare.

The production costs with the purple system are 7 points per hectare. These costs are higher than those of the orange system because implementation requires more equipment or more work. 
4 Ecosystem services:

5 Setting up the purple system contributes to the ecosystem services nature provides.

The total number of hectares cultivated with the purple system by you and your neighbor determines the quality of these services provided by nature.

In other words, the purple system generates additional revenue when it is adopted collectively. you an additional gain (in points) that is equal to twice the cultivated surface. For instance, if both farmers use the purple system to cultivate half their surface, the additional gain is $2 \times(40+40)=160$ points.

\section{Subsidy:}

The subsidy brings you 2 additional points per each hectare you choose to cultivate with the purple crop system.

Comprehension test:

Please answer the following quiz to check you have understood the instructions.

I receive the subsidy only if I cultivate all 80 hectares with the purple system. Please select one answer only:

True / False

Because of the subsidy, I have the same gain regardless of the type of system I choose.

Please select one answer only:

True / False

Results:

You do not need to cultivate the 80 hectares with the purple system to receive the subsidy. The subsidy amounts to 2 points for each hectare cultivated with the purple crop system.

The gain varies according to the type of system because the production costs are different and the subsidy is paid only for the purple system. The additional gain related to the ecosystem services depends upon your choice but also that of your neighbor.

\section{Decision}

You are now able to make a decision for Part 4.

You can click on "Previous" to read the explanations again

You have no calculations to make. These tables indicate your gain depending upon your decision and the total number of hectares cultivated with the purple system. To obtain your total gain, you need to add your individual gain and the additional gain related to the ecosystem services. Remember: 200 points $=€ 1$ 


\begin{tabular}{|c|c|c|c|c|c|}
\hline & \multicolumn{5}{|c|}{ Your farming operation: number of hectares with the purple crop system } \\
\hline & 0 & & 40 & 60 & 80 \\
\hline $\begin{array}{l}\text { Individual } \\
\text { gain } \\
\text { points) }\end{array}$ & 880 & 860 & 840 & 820 & 800 \\
\hline
\end{tabular}

4

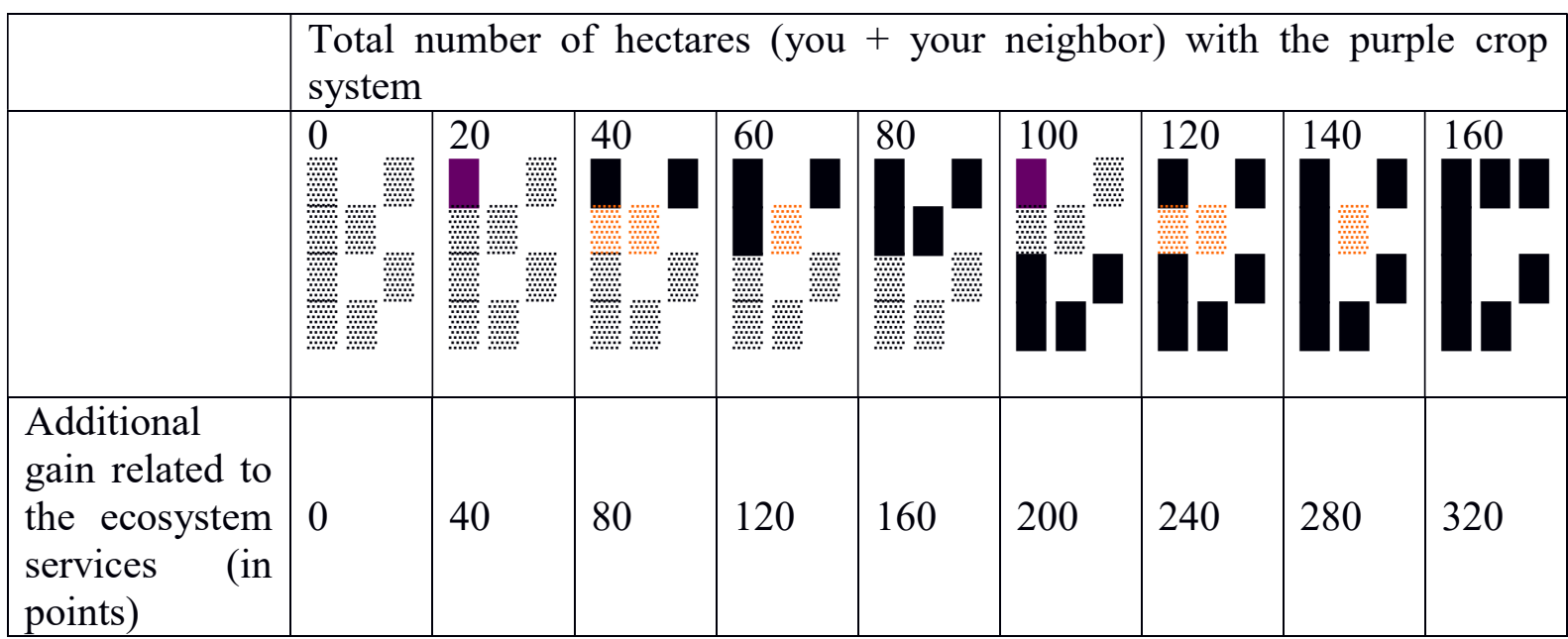

6 Your decision (orange system hectares; purple system hectares)

\begin{tabular}{|l|l|l|l|l|l|}
\hline Hectares with the orange crop system & 0 & 20 & 40 & 60 & 80 \\
\hline Hectares with the purple crop system & 80 & 60 & 40 & 20 & 0 \\
\hline
\end{tabular}

Please select one answer only

9 What do you believe will be your neighbor's decision? (orange system hectares; purple system 10 hectares)

\begin{tabular}{|l|l|l|l|l|l|}
\hline Hectares with the orange crop system & 0 & 20 & 40 & 60 & 80 \\
\hline Hectares with the purple crop system & 80 & 60 & 40 & 20 & 0 \\
\hline
\end{tabular}

Please select one answer only

\section{Treatment 2}

13 This part is similar to the preceding one. The only difference is that a subsidy has been set up for 14 those farmers who undertake to set up the purple crop system.

15 Remember: The points you win in Part 4 will be added to your total of points, then will be converted

16 into euros credited to the gift card, based on the following rate: 200 points $=1$ euro.

Your gain (in points) for Part 4 is determined as follows:

19 Revenue, production costs, and ecosystem services are the same as in the preceding part.

21 Revenue:

22 Your crops bring you a revenue of 15 points per hectare, regardless of the crop system put in place. 
Observations carried out in the farms that have implemented the purple crop system show that the revenue is the same as that of the orange system.

\section{Production costs:}

The orange system production cost is fixed, known, and equal to 4 points per hectare.

In contrast, the purple system production cost is not known in advance. It may increase through adverse events such as unpredictable weather conditions or the onset of diseases.

The computer will randomly determine whether there is an adverse event (a 50/50 chance). The production cost will thus depend upon this random draw. If an adverse event occurs, the cost of the purple system is 9 points per hectare. If no adverse event occurs, the cost of the purple system is 5 points per hectare.

Ecosystem services:

Setting up the purple system contributes to the ecosystem services nature provides.

The total number of hectares cultivated with the purple system by you and your neighbor determines the quality of these services provided by nature.

In other words, the purple system generates additional revenue when it is adopted collectively.

The total number of hectares cultivated with the purple system by you and your neighbor will bring you an additional gain (in points) that is equal to twice the cultivated surface. For instance, if both farmers use the purple system to cultivate half their surface, the additional gain is $2 \times(40+40)=160$ points.

\section{Subsidy:}

The subsidy brings you 2 additional points per each hectare you choose to cultivate with the purple crop system.

\section{Comprehension test:}

Please answer the following quiz to check you have understood the instructions.

I receive the subsidy only if I cultivate all 80 hectares with the purple system. Please select one answer only:

True / False

Because of the subsidy, I have the same gain regardless of the type of system I choose.

Please select one answer only:

True / False

Results:

You do not need to cultivate the 80 hectares with the purple system to receive the subsidy. The subsidy amounts to 2 points for each hectare cultivated with the purple crop system.

The gain varies according to the type of system because the production costs are different and the subsidy is paid only for the purple system. The additional gain related to the ecosystem services depends upon your choice but also that of your neighbor.

\section{Decision}

You are now able to make a decision for Part 4.

You can click on "Previous" to read the explanations again 
2 You have no calculations to make. These tables indicate your gain depending upon your decision and 3 the total number of hectares cultivated with the purple system. To obtain your total gain, you need to 4 add your individual gain and the additional gain related to the ecosystem services. Remember: 200 5 points $=€ 1$

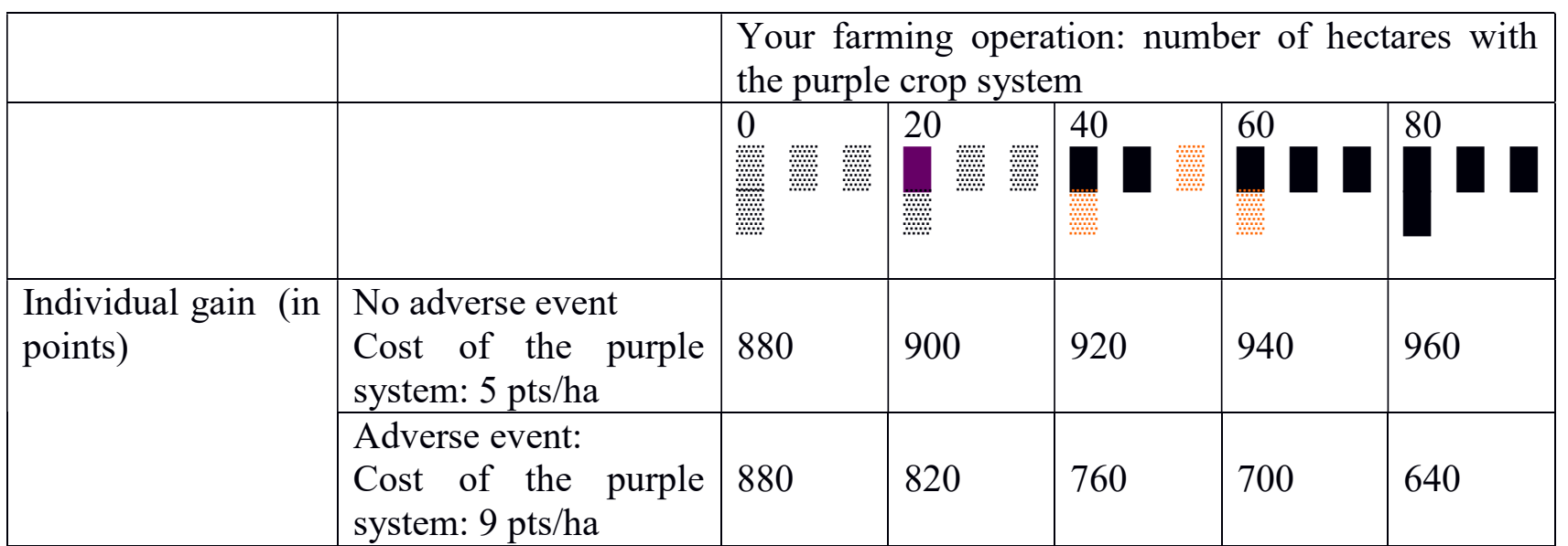

7

8

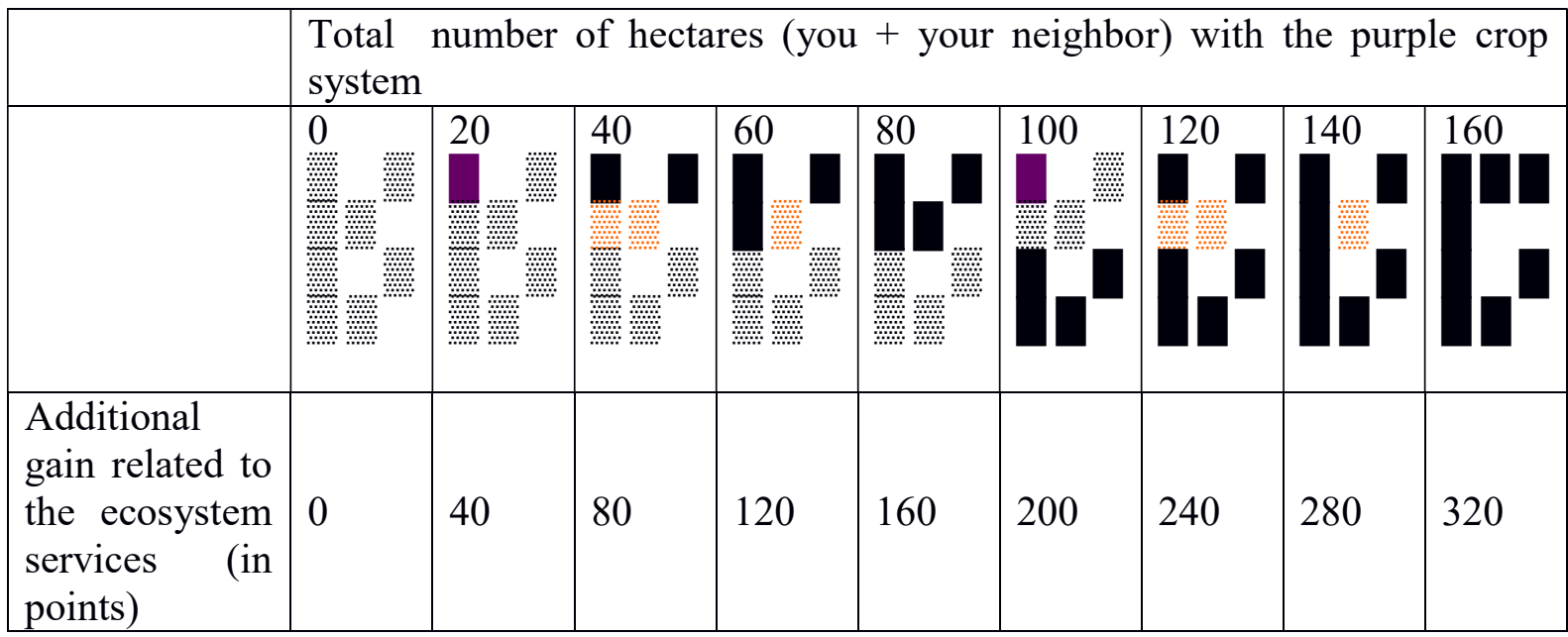

10 Your decision (orange system hectares; purple system hectares)

\begin{tabular}{|l|l|l|l|l|l|}
\hline Hectares with the orange crop system & 0 & 20 & 40 & 60 & 80 \\
\hline Hectares with the purple crop system & 80 & 60 & 40 & 20 & 0 \\
\hline
\end{tabular}

Please select one answer only

13 What do you believe will be your neighbor's decision? (orange system hectares; purple system 14 hectares)

\begin{tabular}{|l|l|l|l|l|l|}
\hline Hectares with the orange crop system & 0 & 20 & 40 & 60 & 80 \\
\hline Hectares with the purple crop system & 80 & 60 & 40 & 20 & 0 \\
\hline
\end{tabular}

Please select one answer only

16 Treatment 3

17 This part is similar to the preceding one. The only difference is that a subsidy has been set up for

18 those farmers who undertake to set up the purple crop system. 
Remember: The points you win in Part 4 will be added to your total of points, then will be converted into euros credited to the gift card, based on the following rate: 200 points $=1$ euro.

Your gain (in points) for Part 3 is determined as follows:

Revenue, production costs, and ecosystem services are the same as in the preceding part.

Revenue:

Your crops bring you the same revenue per hectare, regardless of the crop system put in place. Observations carried out in the farms that have implemented the purple crop system show that the revenue is the same as that of the orange system.

However, the revenue is not known in advance because it can decrease through adverse events that reduce yield and/or prices on the agricultural markets.

The computer will randomly determine whether there is an adverse event (a 50/50 chance). The revenue per hectare will thus depend upon this draw. If an adverse event occurs, the revenue per hectare is 10 points per hectare. If no adverse event occurs, the revenue per hectare is 20 points per hectare.

\section{Production costs:}

The production costs with the orange system are 4 points per hectare.

The production costs with the purple system are 7 points per hectare. These costs are higher than those of the orange system because implementation requires more equipment or more work.

\section{Ecosystem services:}

Setting up the purple system contributes to the ecosystem services nature provides.

The total number of hectares cultivated with the purple system by you and your neighbor determines the quality of these services provided by nature.

In other words, the purple system generates additional revenue when it is adopted collectively.

The total number of hectares cultivated with the purple system by you and your neighbor will bring you an additional gain (in points) that is equal to twice the cultivated surface. For instance, if both farmers use the purple system to cultivate half their surface, the additional gain is $2 \times(40+40)=160$ points.

\section{Subsidy :}

The subsidy brings you 2 additional points per each hectare you choose to cultivate with the purple crop system.

Comprehension test:

Please answer the following quiz to check you have understood the instructions.

I receive the subsidy only if I cultivate all 80 hectares with the purple system.

Please select one answer only:

True / False

Because of the subsidy, I have the same gain regardless of the type of system I choose.

Please select one answer only:

True / False 
23 Your decision (orange system hectares; purple system hectares) Hectares with the orange crop system depends upon your choice but also that of your neighbor.

\section{Decision}

You are now able to make a decision for Part 4.

You can click on "Previous" to read the explanations again points $=€ 1$
I do not need to cultivate the 80 hectares with the purple system to receive the subsidy. The subsidy amounts to 2 points for each hectare cultivated with the purple crop system.

The gain varies according to the type of system because the production costs are different and the subsidy is paid only for the purple system. The additional gain related to the ecosystem services

You have no calculations to make. These tables indicate your gain depending upon your decision and the total number of hectares cultivated with the purple system. To obtain your total gain, you need to add your individual gain and the additional gain related to the ecosystem services. Remember: 200

\begin{tabular}{|c|c|c|c|c|c|c|}
\hline & & \multicolumn{5}{|c|}{$\begin{array}{l}\text { Your farming operation: number of hectares with the } \\
\text { purple crop system }\end{array}$} \\
\hline & & 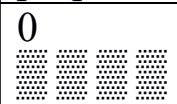 & 20 & 40 & 60 & 80 \\
\hline \multirow[t]{2}{*}{$\begin{array}{l}\text { Individual gain (in } \\
\text { points) }\end{array}$} & $\begin{array}{l}\text { No adverse } \\
\text { event } \\
\text { Revenue: } 20 \\
\text { pts/ha }\end{array}$ & 1280 & 1260 & 1240 & 1220 & 1200 \\
\hline & $\begin{array}{l}\text { Adverse event: } \\
\text { Revenue: } 10 \\
\text { pts/ha }\end{array}$ & 480 & 460 & 440 & 420 & 400 \\
\hline
\end{tabular}

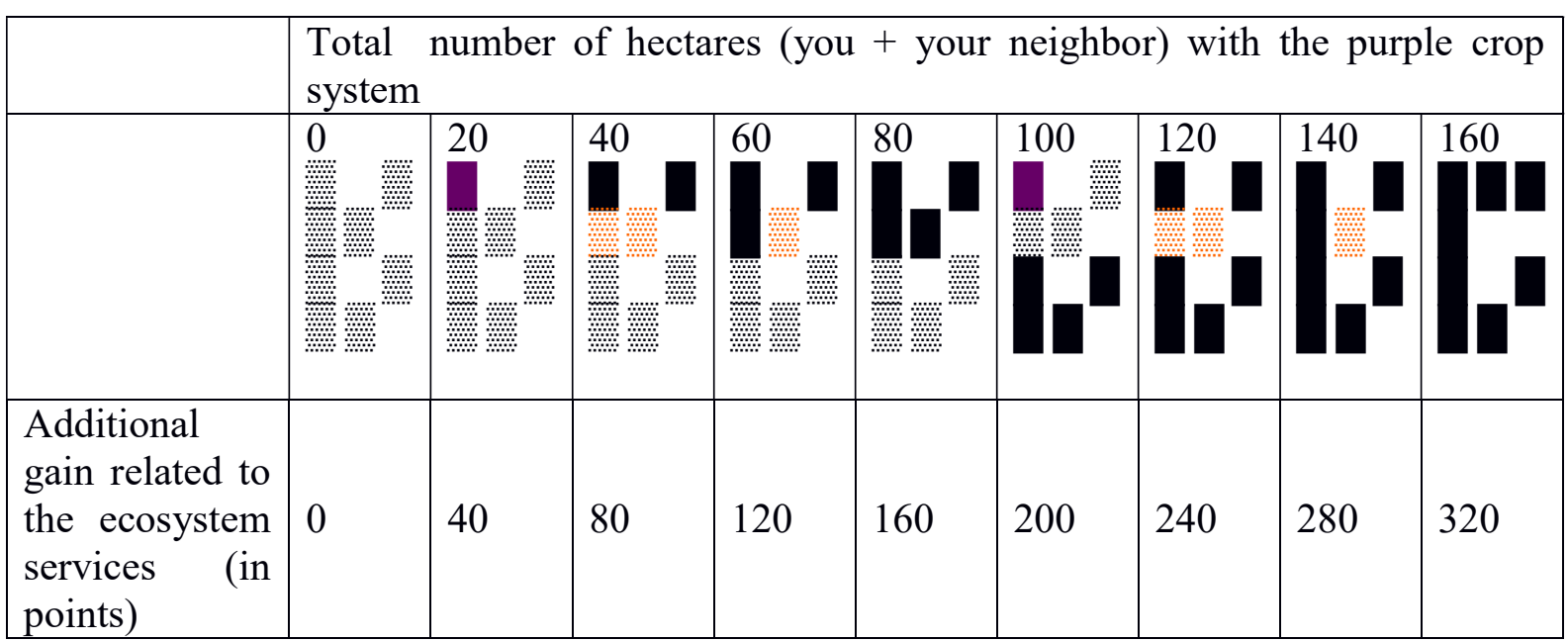




\begin{tabular}{l|l|l|l|l|l|l|}
\hline Hectares with the purple crop system & 80 & 60 & 40 & 20 & 0 \\
\hline
\end{tabular}

3 What do you believe will be your neighbor's decision? (orange system hectares; purple system 4 hectares)

\begin{tabular}{|l|l|l|l|l|l|}
\hline Hectares with the orange crop system & 0 & 20 & 40 & 60 & 80 \\
\hline Hectares with the purple crop system & 80 & 60 & 40 & 20 & 0 \\
\hline
\end{tabular}

\section{Treatment 4}

7 This part is similar to the preceding one. The only difference is that a subsidy has been set up for 8 those farmers who undertake to set up the purple crop system.

9 Remember: The points you win in Part 1 will be added to your total of points, then will be converted into euros credited to the gift card, based on the following rate: 200 points $=1$ euro.

Your gain (in points) for Part 4 is determined as follows:

13 Revenue, production costs, and ecosystem services are the same as in the preceding part.

Revenue:

16 Your crops bring you the same revenue per hectare, regardless of the crop system put in place.

Observations carried out in the farms that have implemented the purple crop system show that the revenue is the same as that of the orange system.

However, the revenue is not known in advance because it can decrease through adverse events that reduce yield and/or prices on the agricultural markets.

The computer will randomly determine whether there is an adverse event (a 50/50 chance). The revenue per hectare will thus depend upon this draw. If an adverse event occurs, the revenue per hectare is 10 points per hectare. If no adverse event occurs, the revenue per hectare is 20 points per hectare.

\section{Production costs:}

The orange system production cost is fixed, known, and equal to 4 points per hectare.

In contrast, the purple system production cost is not known in advance. It may increase through adverse events such as unpredictable weather conditions or the onset of diseases.

The computer will randomly determine whether there is an adverse event that affects the production costs with the purple system occurs or not (a 50/50 chance). The production cost will thus depend upon this random draw. If an adverse event occurs, the cost of the purple system is 9 points per hectare. If no adverse event occurs, the cost of the purple system is 5 points per hectare.

\section{Ecosystem services:}

Setting up the purple system contributes to the ecosystem services nature provides.

The total number of hectares cultivated with the purple system by you and your neighbor determines the quality of these services provided by nature.

In other words, the purple system generates additional revenue when it is adopted collectively. The total number of hectares cultivated with the purple system by you and your neighbor will bring you an additional gain (in points) that is equal to twice the cultivated surface. For instance, if both farmers use the purple system to cultivate half their surface, the additional gain is $2 \times(40+40)=160$ points.

\section{Subsidy :}


The subsidy brings you 2 additional points per each hectare you choose to cultivate with the

Comprehension test:

Please answer the following quiz to check you have understood the instructions.

I receive the subsidy only if I cultivate all 80 hectares with the purple system.

Please select one answer only:

True / False

Because of the subsidy, I have the same gain regardless of the type of system I choose.

Please select one answer only:

True / False

Results:

I do not need to cultivate the 80 hectares with the purple system to receive the subsidy. The subsidy amounts to 2 points for each hectare cultivated with the purple crop system.

The gain varies according to the type of system because the production costs are different and the subsidy is paid only for the purple system. The additional gain related to the ecosystem services depends upon your choice but also that of your neighbor.

Decision

You are now able to make a decision for Part 4.

You can click on "Previous" to read the explanations again

You have no calculations to make. These tables indicate your gain depending upon your decision and the total number of hectares cultivated with the purple system. To obtain your total gain, you need to add your individual gain and the additional gain related to the ecosystem services. Remember: 200 points $=€ 1$

\begin{tabular}{|c|c|c|c|c|c|c|}
\hline & & \multicolumn{5}{|c|}{$\begin{array}{l}\text { Your farming operation: number of } \\
\text { hectares with the purple crop system }\end{array}$} \\
\hline & & 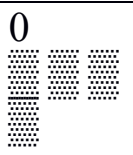 & : & 40 & 60 & 80 \\
\hline \multirow[t]{3}{*}{$\begin{array}{l}\text { Individual gain (in } \\
\text { points) }\end{array}$} & $\begin{array}{l}\text { No adverse event: } \\
\text { High revenue: } 20 \text { pts/ha } \\
\text { Low cost of the purple system: } 5 \\
\text { pts/ha }\end{array}$ & 1280 & 1300 & 1320 & 1340 & 1360 \\
\hline & $\begin{array}{l}\text { An adverse event: } \\
\text { High revenue: } 20 \text { pts/ha } \\
\text { High cost of the purple system : } 9 \\
\text { pts/ha }\end{array}$ & 1280 & 1220 & 1160 & 1100 & 1040 \\
\hline & $\begin{array}{l}\text { An adverse event: } \\
\text { Low revenue: } 10 \mathrm{pts} / \mathrm{ha} \\
\text { Low cost of the purple system: } 5 \\
\text { pts/ha }\end{array}$ & 480 & 500 & 520 & 540 & 560 \\
\hline
\end{tabular}




\begin{tabular}{|l|l|l|l|l|l|l|}
\hline & $\begin{array}{l}\text { Two adverse events } \\
\text { Low revenue: } 10 \text { pts/ha } \\
\text { High cost of the purple system: 9 } \\
\text { pts/ha }\end{array}$ & 480 & 420 & 360 & 300 & 240 \\
\hline
\end{tabular}

7

8 Your decision (orange system hectares; purple system hectares)

\begin{tabular}{|l|l|l|l|l|l|}
\hline Hectares cultivated with the orange crop system & 0 & 20 & 40 & 60 & 80 \\
\hline Hectares cultivated with the purple crop system & 80 & 60 & 40 & 20 & 0 \\
\hline
\end{tabular}

What do you believe will be your neighbor's decision? (orange system hectares; purple system hectares)

\begin{tabular}{|l|l|l|l|l|l|}
\hline Hectares cultivated with the orange crop system & 0 & 20 & 40 & 60 & 80 \\
\hline Hectares cultivated with the purple crop system & 80 & 60 & 40 & 20 & 0 \\
\hline
\end{tabular}

13 Please select one answer only

\section{Part 5}

15 Finally, we would like to have more information about you.

16 Gender

17 Please select one answer only:

18 Masculine

19 Feminine

Year of birth

22 Only numbers may be entered in this field.

Are there any farmers in your family (father, mother, brother, sister, uncle, aunt)?

Please select one answer only:

26 Yes / No 
How many days per year do you spend on a farm?

Please select one answer only:

More than 60 days a year

Between 31 and 60 days a year

Between 5 and 30 days a year

Less than 5 days a year

We would like to know what you think about setting up a crop system similar to the purple system that improves the environmental impact of agricultural production.

Imagine that you are a farmer.

What would prevent you from testing such a system on your farm? Give the main reason.

Please select one answer only:

I fear reduced crop yields, hence reduced income

This means acquiring additional information and skills

I would like to sell my production at a higher price specifying that its environmental impact is reduced, but I fear I may not find markets.

It requires excessive investments.

None of the above

In contrast, what would help you adopt such a system? Give the main reason.

Please select one answer only:

Technical assistance

Financial assistance to invest in the necessary equipment or training

Financial assistance to take out insurance to cover a drop in income

Higher subsidies to make up for the loss of earnings

Joining a group of farmers who collectively undertake this venture

None of the above

Do you think that it is the responsibility of farmers to protect the environment?

Please select one answer only:

strongly disagree

tend to disagree

tend to agree

strongly agree

Do you think that the impact of agricultural practices on the environment is rather negative or positive?

Please select one answer only:

very negative

rather negative

rather positive

very positive

Are you considering becoming a farmer?

Please select one answer only:

Yes, as soon as I've finished school

49 Yes, within the next 10 years

$50 \quad$ Never 
3 What would be the core farming activity?

4 Answer this question only if the following conditions apply: The answer was 'Yes, as soon as I've

farmer?

Please select one answer only:

Cattle for milk only

Cattle for meat and a mix milk-meat

Intensive farming (e.g. pigs, poultry)

Field crops

Market gardening, horticulture and fruit

Viticulture

Other productions

Do you think yours will be a certified organic farm?

Please select one answer only:

Yes / No

Do you think you could join a group of farmers (e.g. CUMA, GDA, CIVAM, GAEC, cooperative) outside an agricultural union?

Please select one answer only:

Yes / No

We cannot tell you your gain immediately because it depends upon the decisions made by another participant and random draws. Once we have the answers given by the participant you were partnered with by random draw, you will receive an email recapping your decisions and your gain for each part, and the final amount that will be credited to your gift card.

Do you wish to receive your gift card?

Please select one answer only:

Yes / No

Do you wish to receive the survey results by email?

Please select one answer only:

Yes / No

Do you wish to take part in other surveys of this type that might be set up by the University of Angers?

Please select one answer only:

Yes / No

Surname:

First name:

Address:

Telephone (optional):

Email address:

The survey is finished. Thank you for your answers.

50 We are available to answer any question or comment by email. 
1 